\title{
Alteration of fatty acid metabolism in the liver, adipose tissue, and testis of male mice conceived through assisted reproductive technologies: fatty acid metabolism in ART mice
}

Li-Ya Wang ${ }^{1,2}$, Fang Le ${ }^{1,2}$, Ning Wang ${ }^{1,2}$, Lei Li ${ }^{3}$, Xiao-Zhen Liu ${ }^{1,2}$, Ying-Ming Zheng ${ }^{1,2}$, Hang-Ying Lou ${ }^{1,2}$, Xiang-Rong $\mathrm{Xu}^{1,2}$, Yun-Long Chen ${ }^{4}$, Xiao-Ming Zhu ${ }^{1,2}$, He-Feng Huang ${ }^{1,2}$ and Fan Jin ${ }^{1,2^{*}}$

\begin{abstract}
Background: Lipid metabolism plays important roles in the whole process of pregnancy. Previous studies have demonstrated abnormalities of lipid metabolism in the placentas of pregnancies obtained by assisted reproductive technology (ART). Therefore, we hypothesized that ART micromanipulation may affect lipid metabolism in offspring, and focused on the fatty acid metabolism in ART male offspring in this study.

Methods: The fatty acid metabolism in the liver, adipose tissue and testis was detected. The comparison between naturally conceived (NC), controlled ovarian hyperstimulation (COH), in vitro fertilization (IVF) and intracytoplasmic sperm injection (ICSI) mice was made to analyze the effect of ART on offspring. The mice models in this study included two age groups: adult group and old group. The fatty acid composition and the expression of lipid metabolism-related genes were analyzed by GC-MS and qRT-PCR.

Results: The fatty acid composition in the liver and adipose tissue were significantly altered in ART mice, but no significant difference was found in the testis. In adipose tissue, ART mice showed decreased monounsaturated fatty acids (MUFAs) and increased polyunsaturated fatty acids (PUFAs) in both adult and old mice, while the alteration of saturated fatty acids (SFAs) in the adult disappeared in the old. In liver, the changes were much complex in adult mice, while increased MUFAs and decreased PUFAs were found in ART old mice. The activities of fatty acid metabolism-related enzymes and the expression of lipogenic and lipolytic proteins changed in ART groups, with the adult mice and old mice showing inconsistent alterations. Further analysis indicated that SFAs was closely associated with the alterations of fatty acid metabolism-related enzyme activities and the expression of lipogenic and lipolytic proteins. Furthermore, we also found that the effect of separated ART treatments on fatty acid metabolism varied with different ages and tissues.
\end{abstract}

Conclusions: ART treatments had effect on the fatty acid composition in adipose tissue and liver of male mice. The alteration of SFAs content was crucial for the regulation of fatty acid composition. These changes might have potential effects on the health of ART male offspring which need further investigation.

Keywords: In vitro fertilization, Intracytoplasmic sperm injection, Fatty acid composition

\footnotetext{
* Correspondence: jinfan@zju.edu.cn

${ }^{1}$ Centre of Reproductive Medicine, Women's Hospital, School of Medicine,

Zhejiang University, Hangzhou 310006, China

${ }^{2}$ Key Laboratory of Reproductive Genetics (Zhejiang), Ministry of Health,

Hangzhou 310006, China

Full list of author information is available at the end of the article
} 


\section{Background}

Assisted reproductive technologies (ART), such as in vitro fertilization (IVF) and intracytoplasmic sperm injection (ICSI), have been successfully applied to solve infertility problems in humans for several decades. However, their potential risks have been a subject of debate. Much evidence has demonstrated that IVF procedures could exert negative effects on developing fetus [1-4]. Pathological abnormalities in placentas associated with ART have also been investigated, including abnormal placental shape, abnormal umbilical cord insertion and increased placental weights $[5,6]$. Moreover, ART-induced impairment of placental steroid metabolism and restricted delivery of steroid hormones from mother to fetus have been reported [7].

Fatty acids are essential regulators in steroid hormone transportation and vital participants in cell signaling pathways $[8,9]$. The liver and adipose tissue play central roles in fatty acid metabolism. The liver acts as a major organ for fatty acid synthesis, while adipose tissue undertakes responsibility for triglyceride storage. The fatty acid composition of adipose tissue is an early determinant of childhood obesity [10], and abnormal lipid metabolism in abdominal adipose tissue may lead to many metabolic syndromes [11-13]. Kennedy A, Martinez K, Chuang CC, LaPoint $\mathrm{K}$ and McIntosh M [14] proposed that elevated saturated fatty acids (SFAs) could enhance adipose tissue expansion, which subsequently activated inflammatory signaling instead of insulin signaling to induce insulin resistance. Another research reported that abnormal fatty acid composition in atherosclerosis probably resulted from an increased fatty acid synthesis of monounsaturase activity [15]. Coronary heart disease and myocardial infarction in old men could be predicted by abnormal fatty acid composition [16,17]. In addition, the reproductive problems were also associated with fatty acid profile. Fatty acids have been shown to participate in oocyte maturation, fertilization, and embryo development [18-20]. Supplementation with polyunsaturated fatty acids (PUFAs) has been shown to delay gestation [21] and influence ovarian and uterine function [22-24]. Additionally, the fatty acid composition in the testis is also a key factor affecting spermatogenesis [25]. Either the decrease in docosahexaenoic acid (DHA, C22:6n-3) or the increase in SFAs have been detected in the sperm of oligozoospermic or asthenozoospermic men [26,27].

During fatty acid metabolism, the synthesis and catabolism of fatty acids are essential for regulating fatty acid composition. De novo lipid synthesis is regulated by fatty acid synthase (FAS) and its upstream ATP citrate lyase (ACLY) and acetyl-coenzyme A carboxylase alpha (ACACA). Carnitine palmitoyltransferase 1(CPT1), a mitochondrial enzyme, mediates the transport of longchain fatty acids across the membrane during beta oxidation. The expression of CPT1 is associated with Type 2 diabetes and insulin resistance [28]. It was reported that the increase in fatty acid synthesis, together with the decrease of fatty acid oxidation suggested lipid accumulation $[29,30]$. The content of SFAs, monounsaturated fatty acids (MUFAs) and PUFAs can be regulated by a series of desaturases and elongases. Their activities were reported to be used for predicting metabolic diseases [31]. Stearoyl-CoA desaturase-1 (SCD1) is ratelimiting enzyme which regulates the balance between SFAs and MUFAs [32]. Long-chain fatty acids family member 6 (Elovl6) catalyzes the synthesis of saturated and monounsaturated fatty acids, and ELOVL6 deficiency may decrease the expressions of lipogeneic and lipid oxidation genes [33].

It was found that some male reproductive disorders occurred to ART offspring. For instance, boys conceived by IVF/ICSI had an increased risk of hypospadias or cryptorchidism and poor sperm quality in adulthood [34]. In addition, a decrease in serum testosterone and an increase in the $\mathrm{LH} /$ testosterone ratio occurred to three-month-old boys conceived by ICSI [35]. Adult man whose mothers received fertility treatment may have lower sperm count and concentration, smaller testis, and a lower free androgen index [36]. The problems in male ART offspring may arise from paternal inheritance or ART treatments. At present, whether ART methods could induce changes of fatty acid metabolism is still unclear. Our previous studies have found increased birth weight, but without abnormal semen quality and testicular morphology in ART mice models (Jin F et al., 2012 unpublished data). Therefore, in this research, we investigated the fatty acid metabolism in the adipose tissue, liver and testis of male ART mice, and analyzed the probable causes for the alterations. Our results provided the evidence of altered fatty acid metabolism in ART conceived mice.

\section{Results}

\section{Fatty acid composition of the mouse diet}

In the mouse diet, SFAs, MUFAs and PUFAs accounted for $21.71 \%, 32.47 \%$, and $45.81 \%$ of the total fatty acids respectively (Figure 1A). Oleic acid (C18:1n-9), linoleic acid (C18:2n-6), palmitic acid (C16:0) and stearic acid (C18:0) were the predominant fatty acids which accounted for $31.63 \%, 45.72 \%, 17.04 \%$ and $4.22 \%$ respectively (Figure 1B).

\section{Fatty acid composition in adipose tissue, liver and testis}

In these three tissues, $\mathrm{C} 16: 0$ and $\mathrm{C} 18: 0$ were the two predominant SFAs. Palmitoleic acid (C16:1n-7) and C18:1n-9 were the main MUFAs. C18:2n-6 was the most abundant PUFA.

In adult testis, compared with NC group, only a little difference was found in ART groups, with a decreased 


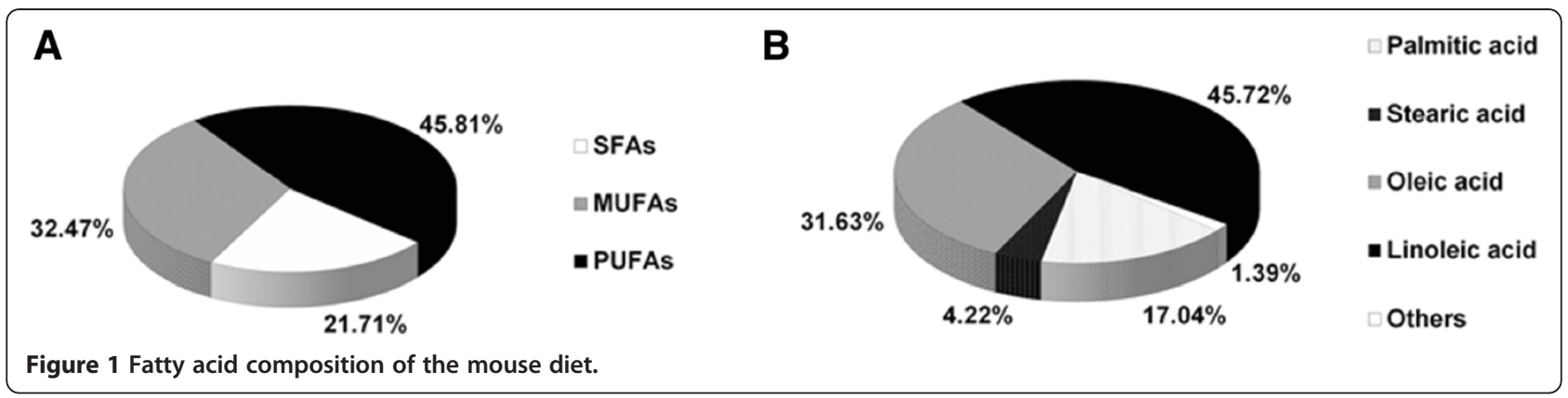

eicosadienoic acid (C20:2n-9) in $\mathrm{COH}$ group and increased $\mathrm{C} 14: 0$ and docosatetraenoic acid (C22:4n-7) in ICSI and IVF group respectively (Table 1). The total SFAs, MUFAs and PUFAs didn't show significant difference between the four groups (data not shown).

In adult adipose tissue, the ART groups contained higher levels (1.47-1.88 fold increase) of C14:0 and lower levels of C18:2n-6 (9.91-20.36\% decrease) than NC group. Compared with $\mathrm{COH}$ group, increased $\mathrm{C} 18: 1 \mathrm{n}-9$ and $C 22: 4 n-7$ and decreased $C 18: 0$ and C18:2n-6 was found in IVF group. Higher content of C14:0 and C18:2n-6 and lower proportion of C22:4n-7 was detected in ICSI group compared with IVF group (Table 2).

In old adipose tissue, compared with $\mathrm{NC}$ group, ART mice contained lower levels of C14:0 (44.44$52.12 \%$ decrease), C14:1n-2 (47.37-63.16\% decrease), C16:1n-9 (21.21-51.51\% decreased), C18:2n-6 (11.10$14.14 \%$ decreased), linelenic acid (C18:3n-6) (66.67-83.33\% decrease) and eicosapentaenoic acid (EPA, C20:5n-3) (55.56-66.67\% decrease) and higher levels of C18:1n-9 (1.15-1.25 fold increase). More C18:1n-9 and less C16:1n-9 and C22:6n-3 was found in IVF group when compared to

Table 1 Fatty acid composition in adult testis

\begin{tabular}{lrrrr}
\hline Adult testis & \multicolumn{1}{c}{ Control } & COH & IVF & ICSI \\
\hline c14:0 & $1.06 \pm 0.30$ & $1.07 \pm 0.23$ & $0.90 \pm 0.21$ & $1.75 \pm 0.67^{* *}$ \\
c16:0 & $26.95 \pm 3.59$ & $28.15 \pm 3.11$ & $28.74 \pm 3.04$ & $26.02 \pm 3.53$ \\
c18:0 & $6.73 \pm 2.15$ & $9.18 \pm 3.67$ & $6.00 \pm 1.87$ & $6.73 \pm 2.19$ \\
c16:1n-7 & $3.83 \pm 0.82$ & $3.78 \pm 0.54$ & $3.56 \pm 1.52$ & $4.38 \pm 1.57$ \\
c18:1n-1 & $0.05 \pm 0.02$ & $0.03 \pm 0.01$ & $0.06 \pm 0.03$ & $0.04 \pm 0.01$ \\
c18:1n-9 & $25.15 \pm 2.76$ & $21.70 \pm 3.57$ & $24.19 \pm 4.90$ & $24.24 \pm 2.77$ \\
c18:2n-6 & $25.31 \pm 5.15$ & $21.91 \pm 6.53$ & $19.79 \pm 6.44$ & $27.03 \pm 7.32$ \\
c20:2n-9 & $0.58 \pm 0.18$ & $0.39 \pm 0.12^{*}$ & $0.39 \pm 0.09$ & $0.47 \pm 0.13$ \\
c20:3n-6 & $0.61 \pm 0.25$ & $0.60 \pm 0.14$ & $0.70 \pm 0.33$ & $0.49 \pm 0.22$ \\
c20:4n-6 & $4.14 \pm 1.14$ & $4.98 \pm 1.50$ & $5.79 \pm 2.84$ & $3.89 \pm 1.89$ \\
c22:4n-7 & $0.61 \pm 0.23$ & $1.09 \pm 0.33$ & $1.19 \pm 0.40^{*}$ & $0.63 \pm 0.37$ \\
c22:6n-3 & $4.99 \pm 2.21$ & $7.11 \pm 2.46$ & $8.68 \pm 4.67$ & $4.33 \pm 3.59$ \\
\hline
\end{tabular}

The numbers reflect the percentages of total fatty acid methyl esters. The fatty acids whose content were more than $0.01 \%$ were shown in our data. $P<0.05$ vs. NC group; ${ }^{* *} P<0.01$ vs. NC group. Data are presented as the means \pm SD.
$\mathrm{COH}$ group. ICSI group presented higher content of C18:0, C20:1n-9, C22:4n-7 and C22:6n-3 than IVF group (Table 3).

In adult adipose tissue, an up-regulated SFAs (1.121.13 fold increase) and MUFAs (1.05-1.16 fold increase) and a down-regulate PUFAs (10.5-19.88\% decrease) existed in ART groups. IVF group had more MUFAs and less PUFAs than $\mathrm{COH}$ and ICSI group. In old adipose tissue, ART groups showed 1.08-1.16 fold increased MUFAs and 9.59-14.77\% decreased PUFAs (Figure 2). The fatty acid composition in adult mice changed with age, and inconsistent variation of SFAs, MUFAs and PUFAs was shown in $\mathrm{NC}, \mathrm{COH}, \mathrm{IVF}$ and ICSI group.

Table 2 Fatty acid composition in adult adipose tissue

\begin{tabular}{lcccc}
\hline $\begin{array}{l}\text { Adult } \\
\text { adipose } \\
\text { tissue }\end{array}$ & NC & COH & IVF & ICSI \\
\hline C14:0 & $1.00 \pm 0.12$ & $1.47 \pm 0.39$ & $1.60 \pm 0.18^{*}$ & $1.88 \pm 0.77^{* / b}$ \\
C16:0 & $20.05 \pm 1.28$ & $21.88 \pm 1.01$ & $22.17 \pm 0.32$ & $21.75 \pm 1.90$ \\
C18:0 & $2.14 \pm 0.26$ & $2.64 \pm 0.24$ & $2.11 \pm 0.22^{\text {a }}$ & $2.57 \pm 0.57$ \\
C20:0 & $0.05 \pm 0.01$ & $0.05 \pm 0.01$ & $0.07 \pm 0.02$ & $0.07 \pm 0.03$ \\
C14:1n-2 & $0.18 \pm 0.04$ & $0.14 \pm 0.04$ & $0.16 \pm 0.01$ & $0.17 \pm 0.03$ \\
C16:1n-7 & $4.53 \pm 0.85$ & $5.45 \pm 1.36$ & $5.59 \pm 0.56$ & $5.01 \pm 1.30$ \\
C16:1n-9 & $0.20 \pm 0.03$ & $0.23 \pm 0.05$ & $0.22 \pm 0.002$ & $0.21 \pm 0.03$ \\
C18:1n-9 & $29.36 \pm 3.54$ & $29.97 \pm 1.36$ & $33.65 \pm 0.45^{* / a}$ & $30.70 \pm 2.33$ \\
C20:1n-9 & $0.50 \pm 0.12$ & $0.60 \pm 0.06$ & $0.79 \pm 0.20$ & $0.75 \pm 0.22$ \\
C18:2n-6 & $40.28 \pm 1.85$ & $36.29 \pm 0.99^{* *}$ & $32.08 \pm 0.87^{* * / a a}$ & $35.44 \pm 1.22^{* * / b b}$ \\
C18:3n-6 & $0.11 \pm 0.03$ & $0.10 \pm 0.02$ & $0.08 \pm 0.02$ & $0.07 \pm 0.02$ \\
C20:2n-6 & $0.12 \pm 0.01$ & $0.11 \pm 0.01$ & $0.14 \pm 0.04$ & $0.15 \pm 0.06$ \\
C20:3n-6 & $0.19 \pm 0.02$ & $0.16 \pm 0.01$ & $0.15 \pm 0.04$ & $0.15 \pm 0.04$ \\
C20:4n-6 & $0.32 \pm 0.05$ & $0.25 \pm 0.05$ & $0.20 \pm 0.07^{*}$ & $0.21 \pm 0.06^{*}$ \\
C20:5n-3 & $0.26 \pm 0.03$ & $0.23 \pm 0.03$ & $0.27 \pm 0.06$ & $0.24 \pm 0.04$ \\
C22:4n-7 & $0.17 \pm 0.01$ & $0.12 \pm 0.04^{*}$ & $0.26 \pm 0.07^{* / a a}$ & $0.18 \pm 0.06^{b}$ \\
C22:6n-3 & $0.54 \pm 0.02$ & $0.33 \pm 0.04^{*}$ & $0.47 \pm 0.15$ & $0.44 \pm 0.15^{*}$ \\
\hline
\end{tabular}

The numbers reflect the percentages of total fatty acid methyl esters. The fatty acids whose content were more than $0.01 \%$ were shown in our data. $P<0.05$ vs. NC group; ${ }^{* *} P<0.01$ vs. NC group; ${ }^{a} P<0.05$ vs. $\mathrm{COH}$ group; ${ }^{\text {aa }} P<0.01$ vs. $\mathrm{COH}$ group; ${ }^{\mathrm{b}} P<0.05$ vs. IVF group; ${ }^{\mathrm{bb}} P<0.01$ vs. IVF group. Data are presented as the means $\pm S D$. 
Table 3 fatty acid composition in old adipose tissue

\begin{tabular}{|c|c|c|c|c|}
\hline $\begin{array}{l}\text { Old } \\
\text { adipose } \\
\text { tissue }\end{array}$ & NC & $\mathrm{COH}$ & IVF & ICSI \\
\hline C14:0 & $1.17 \pm 0.31$ & $0.65 \pm 0.14^{* *}$ & $0.56 \pm 0.07^{* *}$ & $0.65 \pm 0.15^{* *}$ \\
\hline C16:0 & $17.11 \pm 2.91$ & $16.93 \pm 0.85$ & $16.71 \pm 0.57$ & $16.69 \pm 2.59$ \\
\hline C18:0 & $1.93 \pm 0.90$ & $1.89 \pm 0.47$ & $2.13 \pm 0.41$ & $3.26 \pm 1.49^{b}$ \\
\hline $20: 0$ & $0.03 \pm 0.02$ & $0.04 \pm 0.02$ & $0.05 \pm 0.04$ & $0.11 \pm 0.08^{*}$ \\
\hline C14:1n-2 & $0.19 \pm 0.04$ & $0.10 \pm 0.02^{* *}$ & $0.07 \pm 0.03^{* *}$ & $0.08 \pm 0.02^{* *}$ \\
\hline C16:1n-7 & $6.60 \pm 1.91$ & $6.32 \pm 1.92$ & $5.17 \pm 1.35$ & $3.65 \pm 0.57^{*}$ \\
\hline C16:1n-9 & $0.33 \pm 0.06$ & $0.26 \pm 0.02^{*}$ & $0.16 \pm 0.04^{* * / a a}$ & $0.19 \pm 0.02^{* *}$ \\
\hline C18:1n-9 & $33.17 \pm 2.05$ & $38.29 \pm 0.76^{* *}$ & $41.43 \pm 1.85^{* * / a}$ & $39.06 \pm 2.12^{* *}$ \\
\hline C20:1n-9 & $0.66 \pm 0.23$ & $0.64 \pm 0.22$ & $0.66 \pm 0.24$ & $1.23 \pm 0.62^{* / 16}$ \\
\hline$C 18: 2 n-6$ & $37.70 \pm 2.89$ & $33.96 \pm 1.55^{*}$ & $32.37 \pm 1.48^{* *}$ & $33.92 \pm 2.07^{*}$ \\
\hline C18:3n-6 & $0.06 \pm 0.02$ & $0.02 \pm 0.01^{* *}$ & $0.01 \pm 0.01^{* *}$ & $0.02 \pm 0.01^{* *}$ \\
\hline$C 20: 2 n-6$ & $0.05 \pm 0.03$ & $0.09 \pm 0.02$ & $0.08 \pm 0.03$ & $0.13 \pm 0.06^{* *}$ \\
\hline$C 20: 3 n-6$ & $0.18 \pm 0.03$ & 0.13 & $0.10 \pm 0.02^{*}$ & $0.15 \pm 0.04$ \\
\hline$C 20: 4 n-6$ & $0.18 \pm 0.04$ & $0.17 \pm 0.03$ & $0.16 \pm 0.04$ & $0.19 \pm 0.12$ \\
\hline$C 20: 5 n-3$ & $0.18 \pm 0.06$ & $0.08 \pm 0.01^{* *}$ & $0.06 \pm 0.03^{* *}$ & $0.06 \pm 0.04^{* *}$ \\
\hline$C 22: 4 n-7$ & $0.16 \pm 0.05$ & $0.14 \pm 0.04$ & $0.12 \pm 0.03$ & $0.22 \pm 0.06^{b}$ \\
\hline$C 22: 6 n-3$ & $0.30 \pm 0.10$ & $0.30 \pm 0.01$ & $0.17 \pm 0.07^{\mathrm{a}}$ & $0.39 \pm 0.15^{b}$ \\
\hline
\end{tabular}

The numbers reflect the percentages of total fatty acid methyl esters. The fatty acids whose content were more than $0.01 \%$ were shown in our data. ${ }^{*} P<0.05$ vs. NC group; ${ }^{* *} P<0.01$ vs. NC group; ${ }^{\text {a }} P<0.05$ vs. $\mathrm{COH}$ group; ${ }^{a} P<0.01$ vs. $\mathrm{COH}$ group; ${ }^{\mathrm{b}} P<0.05$ vs. IVF group. Data are presented as the means \pm SD.

In adult liver, $\mathrm{C} 16: 0$, eicosatrienoic acid (C20:3n-6) and arachidonic acid (AA, C20:4n-6) were higher in $\mathrm{COH}$ group than $\mathrm{NC}$ group. Compared with $\mathrm{COH}$ group, an increased C16:0 and C22:4n-7 and a decreased C18:2n- 6 and C20:4n-6 was found in IVF group. Moreover, ICSI group showed an up-regulated C16:1n-7 and down-regulated C20:4n-6, C22:4n-7 and C22:6n-3 compared with IVF group (Table 4).

In old liver, the difference between $\mathrm{NC}$ and ART groups mainly concentrated on $\mathrm{COH}$ and IVF group which had lower content of C16:0 and higher content of C18:1n-9, and the content of all PUFAs (except C18:2n-6) was lower than $\mathrm{NC}$ group. ICSI group showed higher proportion of C18:0 and lower proportion of C20:4n-6, C22:4n-7 and C22:6n-3 than NC group. Compared with $\mathrm{COH}$ group, only $\mathrm{C} 22: 4 \mathrm{n}-7$ and $\mathrm{C} 22: 6 \mathrm{n}-3$ had decreased content in IVF group. The fatty acid composition in ICSI group was totally different from that in IVF group except C16:1n-7and C18:2n-6 (Table 5).

For the total content of SFAs, MUFAs and PUFAs in adult liver, $\mathrm{COH}$ group had a lower content of SFAs and a higher content of PUFAs than NC group, while ICSI group contained increased MUFAs and decreased PUFAs. Compared with $\mathrm{COH}$ group, up-regulated SFAs and MUFAs and down-regulated PUFAs was found in IVF group. The difference between IVF and ICSI group was only represented in the content of MUFAs. In old liver, $\mathrm{COH}$ and IVF group contained more MUFAs and less SFAs and PUFAs than NC group, but no difference existed between $\mathrm{COH}$ and IVF group. ICSI group showed higher content of SFAs than IVF group and lower level of MUFAs than NC and IVF group (Figure 3). The fatty acid composition in adult mice changed with age, and inconsistent variation of SFAs, MUFAs and PUFAs was shown in NC, $\mathrm{COH}$, IVF and ICSI group.

\section{The activities of fatty acid metabolism-related enzymes}

In adipose tissue, $\mathrm{C} 16: 0 / \mathrm{C} 18: 2$ in three adult ART groups were higher than that in $\mathrm{NC}$ group. C16:0/C18:2 in ART groups decreased with age (Figure 4A). In liver, C16:0/ C18:2 showed no difference between the four adult groups. $\mathrm{C} 16: 0 / \mathrm{C} 18: 2$ in old $\mathrm{COH}$ group was lower than that in $\mathrm{NC}$ group, and the ratio in $\mathrm{NC}, \mathrm{COH}$ and ICSI groups increased with age (Figure 4B).

In adipose tissue, C18:0/C16:0 in old ICSI group was significant higher than that in NC and IVF old group. C18:1/C16:1 was up-regulated in old IVF and ICSI group compared to NC group. Both C18:0/C16:0 and C18:1/ C16:1 in ICSI group increased with age (Figure 5A). In liver, $\mathrm{C} 18: 0 / \mathrm{C} 16: 0$ in adult $\mathrm{COH}$ group was higher than that in NC and IVF group. C18:0/C16:0 in adult ICSI group was lower than that in NC group. ICSI old group showed increased C18:0/C16:0 compared with NC and IVF group. C18:0/C16:0 in NC, $\mathrm{COH}$ and IVF groups were down-regulated with age. Compared with adult NC group, $\mathrm{C} 18: 1 / \mathrm{C} 16: 1$ was higher in $\mathrm{COH}$ group and lower in ICSI group. $\mathrm{COH}$ and IVF old group presented enhanced C18:1/C16:1 in comparison with NC group. C18:1/C16:1 in $\mathrm{NC}$ and $\mathrm{COH}$ group decreased with age (Figure 5B).

In adipose tissue, C16:1/C16:0 in old ICSI group was lower than that in NC group. C16:1/C16:0 in NC group was down-regulated with age, while $\mathrm{C} 18: 1 / \mathrm{C} 18: 0$ in $\mathrm{COH}$ was up-regulated with age (Figure 6A). In liver, C16:1/C16:0 in NC, $\mathrm{COH}$ and IVF groups increased with age, but no difference was shown between the four groups in the same age group. $\mathrm{C} 18: 1 / \mathrm{C} 18: 0$ in old $\mathrm{COH}$ and IVF group was up-regulated compared with $\mathrm{NC}$ group. Old IVF group presented higher C18:1/C18:0 than $\mathrm{COH}$ and ICSI group. $\mathrm{C} 18: 1 / \mathrm{C} 18: 0$ in $\mathrm{COH}$ and IVF group increased with age (Figure 6B).

\section{Correlation analysis of lipid metabolism in adult and old mice}

To investigate the influence of varied fatty acid metabolism-related enzyme activities on the fatty acid composition, we analyzed the correlation between fatty acids proportion and the activities of lipid metabolismrelated enzymes. Their correlation weren't always consistent between two age groups in both adipose tissue 


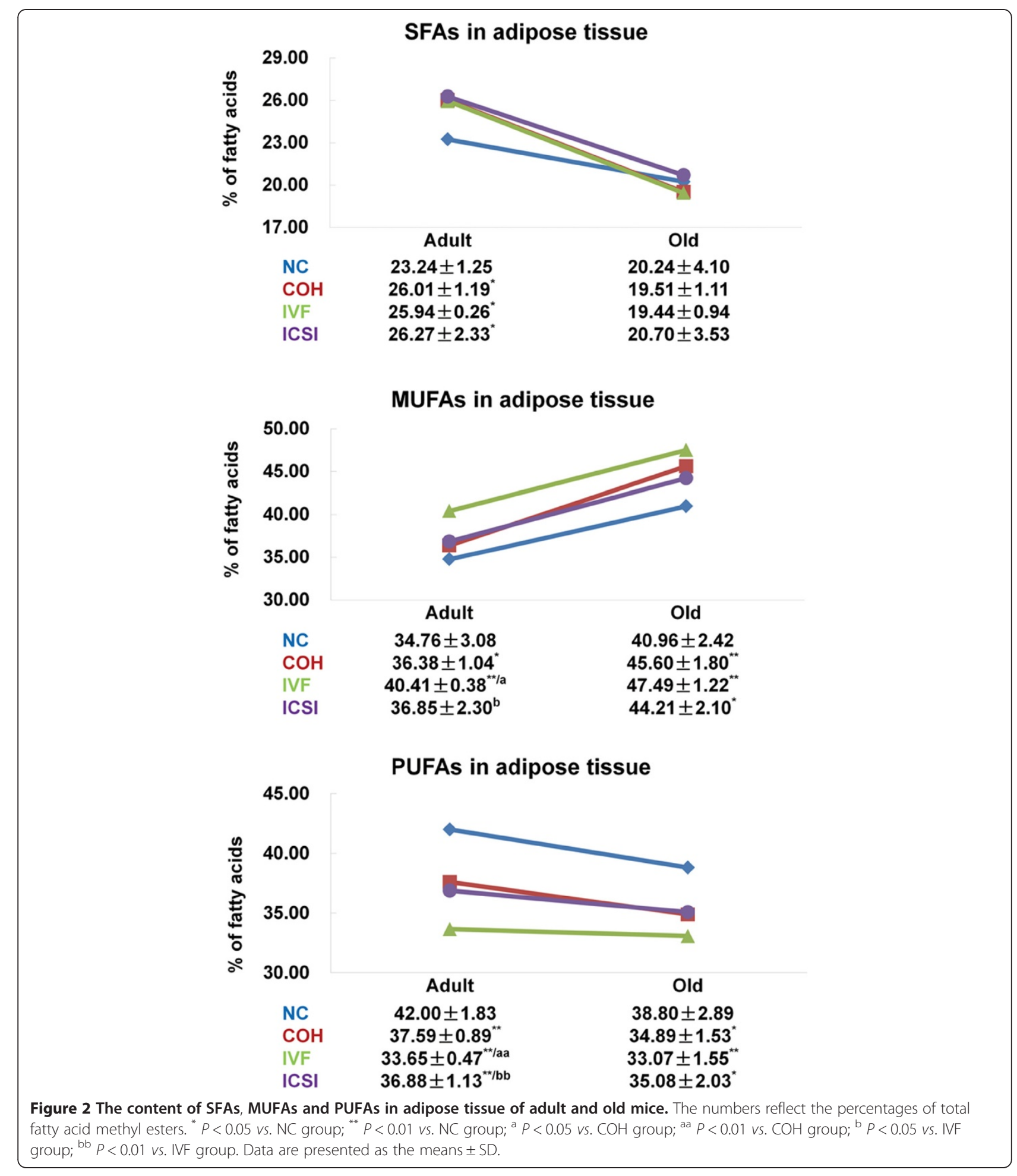

and liver. For instance, in liver, the correlation between C16:0/C18:2 and SFAs, C16:0/C18:2 and PUFAs, and MUFAs and C18:1/C18:0 were consistent in adult and old mice, while the correlation between the estimated SCD1 activities and SFAs were inconsistent. Furthermore, the opposite state between two ages was also existed in liver, such as the correlation between MUFAs and C16:0/C18:2n-6, MUFAs and C18:1/C16:1, PUFAs and C18:0/C16:0, and between PUFAs and C16:1/C16:0 (Additional file 1: Table S1).

To analyze the crucial factor that resulted in the inconsistent correlation, especially the opposite correlation 
Table 4 Fatty acid composition in adult liver

\begin{tabular}{lcccc}
\hline $\begin{array}{l}\text { Adult } \\
\text { liver }\end{array}$ & NC & COH & IVF & ICSI \\
\hline C16:0 & $28.48 \pm 1.59$ & $25.19 \pm 0.33^{* *}$ & $29.32 \pm 0.34^{\text {aa }}$ & $29.33 \pm 0.94$ \\
C18:0 & $16.50 \pm 0.87$ & $17.37 \pm 0.71$ & $16.41 \pm 0.99$ & $15.14 \pm 0.90^{*}$ \\
C16:1n-7 & $0.56 \pm 0.12$ & $0.37 \pm 0.07$ & $0.67 \pm 0.26$ & $0.99 \pm 0.27^{* * / b}$ \\
C18:1n-9 & $14.45 \pm 2.30$ & $12.83 \pm 0.71$ & $15.29 \pm 1.37$ & $17.69 \pm 1.31^{* *}$ \\
C18:2n-6 & $21.70 \pm 1.71$ & $21.19 \pm 1.29$ & $17.39 \pm 0.27^{* * / a a}$ & $20.36 \pm 1.84^{\mathrm{b}}$ \\
C20:3n-6 & $0.67 \pm 0.15$ & $0.91 \pm 0.20^{*}$ & $0.89 \pm 0.07$ & $0.84 \pm 0.18$ \\
C20:4n-6 & $8.91 \pm 0.60$ & $12.30 \pm 0.89^{* *}$ & $9.69 \pm 0.31^{\text {aa }}$ & $7.94 \pm 0.68^{* / b b}$ \\
C22:4n-7 & $0.68 \pm 0.11$ & $0.73 \pm 0.11$ & $0.97 \pm 0.15^{* * / a}$ & $0.73 \pm 0.16^{\mathrm{b}}$ \\
C22:6n-3 & $8.05 \pm 3.68$ & $9.11 \pm 0.70$ & $9.38 \pm 1.30$ & $6.98 \pm 0.76^{\mathrm{b}}$ \\
\hline
\end{tabular}

The numbers reflect the percentages of total fatty acid methyl esters. The fatty acids whose content were more than $0.01 \%$ were shown in our data. ${ }^{*} P<0.05$ vs. NC group; ${ }^{* *} P<0.01$ vs. NC group; ${ }^{a} P<0.05$ vs. $\mathrm{COH}$ group; ${ }^{\text {aa }} P<0.01$ vs. $\mathrm{COH}$ group; ${ }^{\mathrm{b}} P<0.05$ vs. IVF group; ${ }^{\mathrm{bb}} P<0.01$ vs. IVF group. Data are presented as the means \pm SD.

mentioned above, the relationship between all fatty acid and ELOVL6, SCD1 activities and de novo synthesis index were detected in both adult and old mice. In liver, the correlation between C18:1n-9 and C18:1/C16:1, C20:4n-6 and C18:1/C16:1, and between C16:1n-7 and C16:0/C18:2n-6 in adult mice was opposite to that in old mice. Coincidentally, the contrary relationship also existed between these three fatty acids (C16:1n-7, C18:1n-9 and C20:4n-6) and C16:0 (Table 6). In adipose tissue, although we didn't found the opposite state between two age groups when analyzing the correlation between the activities of lipid metabolism-related enzymes ( $\Delta 5$ and $\Delta 6$ desaturases were also analyzed, data were not shown) and SFAs, MUFAs or PUFAs (Additional file 1: Table S1), the contrary relationship between these enzymes activities and individual PUFAs were found. These individual PUFAs (C20:2n-6, C20:4n-6 and $\mathrm{C} 22: 4 \mathrm{n}-7)$ were positively related to $\mathrm{C} 18: 0$ in adult

Table 5 Fatty acid composition in old liver

\begin{tabular}{lcccc}
\hline Old liver & NC & COH & IVF & ICSI \\
\hline C16:0 & $41.33 \pm 1.30$ & $35.01 \pm 1.18^{* *}$ & $32.53 \pm 4.65^{* *}$ & $39.15 \pm 4.67^{\mathrm{b}}$ \\
C18:0 & $14.03 \pm 1.87$ & $13.11 \pm 2.31$ & $11.42 \pm 3.99$ & $19.31 \pm 3.38^{* / \mathrm{bb}}$ \\
C16:1n-7 & $1.84 \pm 0.59$ & $1.50 \pm 0.34$ & $1.99 \pm 0.99$ & $1.32 \pm 0.52$ \\
C18:1n-9 & $16.07 \pm 2.52$ & $30.21 \pm 2.25^{* *}$ & $33.87 \pm 3.26^{* *}$ & $19.86 \pm 0.68^{\mathrm{bb}}$ \\
C18:2n-6 & $12.21 \pm 1.20$ & $14.26 \pm 2.23$ & $15.47 \pm 5.32$ & $10.52 \pm 1.70$ \\
C20:3n-6 & $1.37 \pm 0.15$ & $0.71 \pm 0.09^{* *}$ & $0.63 \pm 0.25^{* *}$ & $1.32 \pm 0.07^{\mathrm{bb}}$ \\
C20:4n-6 & $9.28 \pm 0.76$ & $3.86 \pm 0.56^{* *}$ & $3.36 \pm 1.31^{* *}$ & $6.76 \pm 0.36^{* / / b b}$ \\
C22:4n-7 & $0.98 \pm 0.10$ & $0.29 \pm 0.04^{* *}$ & $0.16 \pm 0.04^{* * / a a}$ & $0.39 \pm 0.03^{* * / b b}$ \\
C22:6n-3 & $2.89 \pm 0.34$ & $1.04 \pm 0.14^{* *}$ & $0.56 \pm 0.13^{* * / a}$ & $1.37 \pm 0.11^{* * / b b}$ \\
\hline
\end{tabular}

The numbers reflect the percentages of total fatty acid methyl esters. The fatty acids whose content were more than $0.01 \%$ were shown in our data. ${ }^{*} P<0.05$ vs. NC group; ${ }^{* *} P<0.01$ vs. NC group; ${ }^{a} P<0.05$ vs. $\mathrm{COH}$ group; ${ }^{a}$ a $P<0.01$ vs. $\mathrm{COH}$ group; ${ }^{\mathrm{b}} P<0.05$ vs. IVF group; ${ }^{\text {bb }} P<0.01$ vs. IVF group. Data are presented as the means $\pm S D$. adipose tissue, but negatively associated with C18:0 in old adipose tissue (Table 7).

\section{The expression of genes that influence fatty acid synthesis and catabolism}

In adult adipose tissue, the expression levels of Fasn, Acly and Acaca in three ART groups were higher than those in NC group, except Acaca in IVF group. Cpt1b in $\mathrm{COH}$ and ICSI group was significantly lower than that in $\mathrm{NC}$ group. Compared with $\mathrm{COH}$ group, $\mathrm{Cpt} 1 b$ was enhanced in IVF group. ICSI group contained higher levels of Fasn and Acaca and lower level of Cpt1b than IVF group (Figure 7A). In old adipose tissue, the expressions of Fasn, Acly and Acaca in ART groups significantly decreased when compared with NC group. Cpt1b was up-regulated in $\mathrm{COH}$ and IVF group and downregulated in ICSI group in comparison with $\mathrm{NC}$ group. Fasn and Acaca in IVF group were expressed at lower level than those in $\mathrm{COH}$ group, while $\mathrm{Cpt} 1 b$ were expressed at higher level. The expressions of all the four genes in ICSI group were reduced in comparison with those in IVF group (Figure 7B). When compared with adult adipose tissue, increased Fasn, Acly and Acaca and decreased Cpt1b were found in old NC mice. The expression of Fasn and Acaca decreased in old $\mathrm{COH}$ and IVF group. All the four genes had lower expression levels in old ICSI group (Figure 8).

In adult liver, compared with NC group, Acly was downregulated and $\mathrm{Cpt1a}$ was up-regulated in $\mathrm{COH}$ group. Fasn and Acly had higher expressions, while Cpt1a and mitochondrial HMG-CoA synthase 2 (Hmgsc2) had lower expressions in IVF group. All the five genes in ICSI group showed increased expressions in comparison with $\mathrm{NC}$ group. Compared with $\mathrm{COH}$ group, the gene expression levels of Fasn and Acly were higher while Cpt1b and Hmgsc2 were lower in IVF group. All these five genes in ICSI group had higher expressions than those in IVF group (Figure 9A). In old liver, compared with $\mathrm{NC}$ group, Fasn, Acly and Acaca were reduced in all three ART groups. Cpt1a and Hmgsc2 were increased in $\mathrm{COH}$ and IVF group, but decreased in ICSI group. In ICSI group, Fasn was up-regulated and Cpt1a and Hmgcs2 were down-regulated when compared with IVF group (Figure 9B). In the comparison between two age groups, the expressions of Acly, Acaca, Cpt1a and Hmgcs2 were higher in old NC liver than those in adult liver. $\mathrm{COH}$ and IVF had lower expressions of Fasn, Acly and Acaca and higher expressions of Cpt1a and Hmgsc2 in old liver. All the five genes were down-regulated in ICSI group with age (Figure 10).

\section{Discussion}

Fatty acid composition in tissues can be changed with many factors [37]. The mice with the same age, sex and 


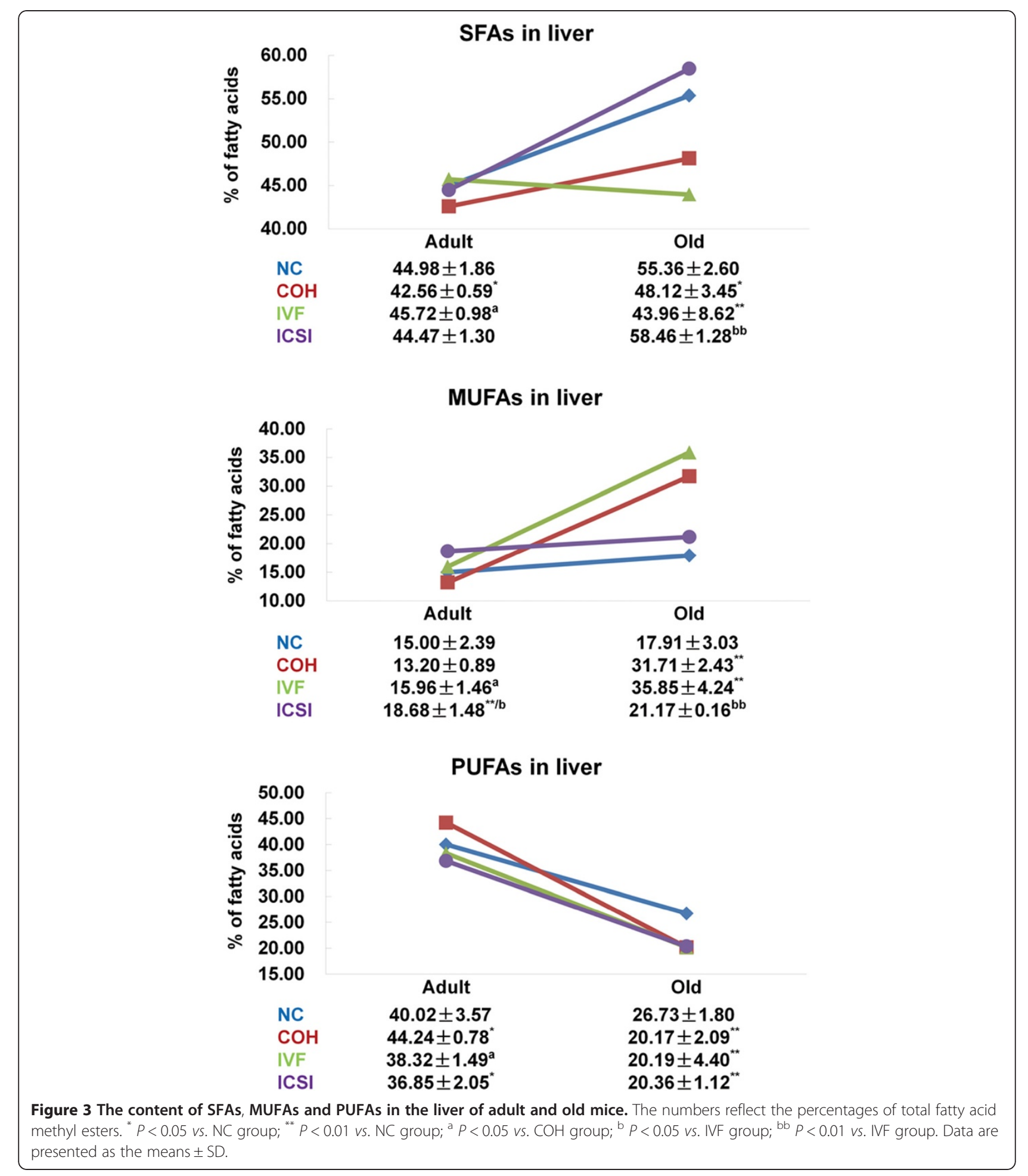

genetic background were chosen in this study, and the diet was also unified to secure difference data from different groups have a good comparability. The four predominant fatty acids (C16:0, C18:0, C18:1n-9 and $\mathrm{C} 18: 2 \mathrm{n}-6)$ and their content in the adipose tissue was quite similar to the fatty acid profile in the mouse diet, which support the main functions of adipose tissue in reserving energy and fatty acid storage. Fatty acid composition of dietary fat influences the lipid composition of adipose tissue $[38,39]$. Previous studies have shown that the molecular species composition of triacylglycerides in mammalian adipose tissues broadly reflected that of 


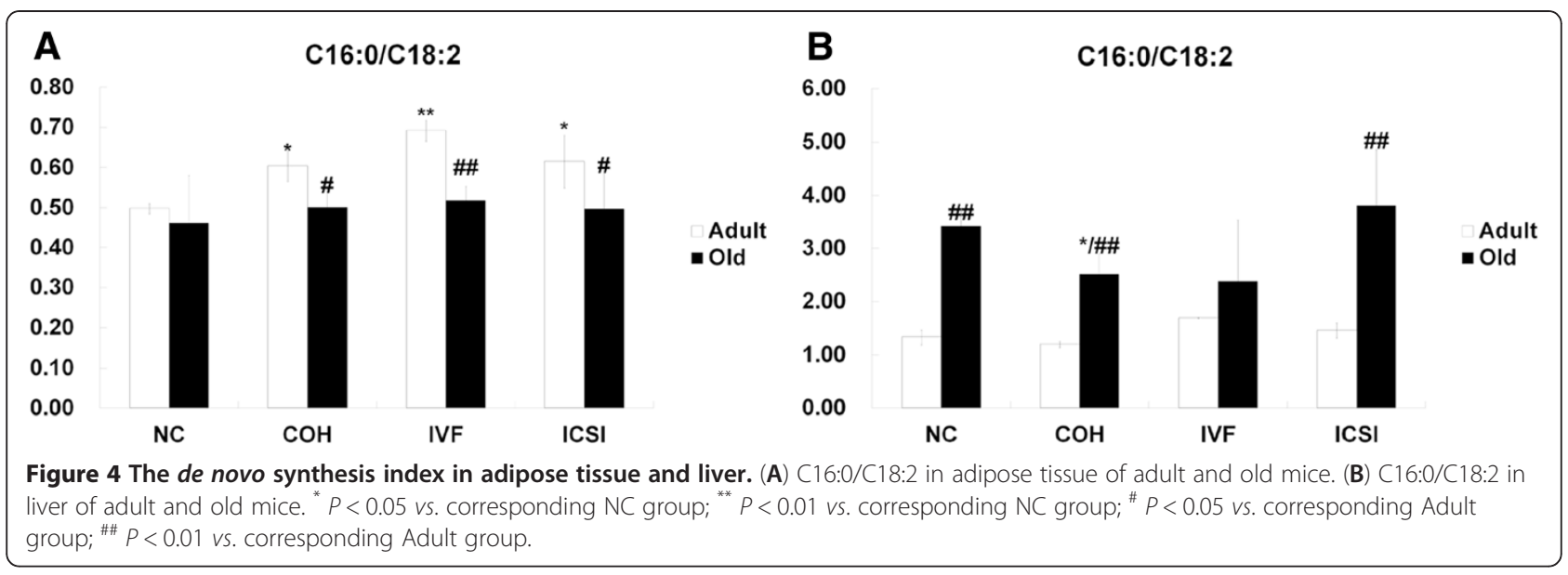

dietary triacylglycerides $[40,41]$, which was further supported by our data. In contrast, the fatty acid composition in the liver and testis was obviously different. Specifically, both the liver and the testis contain significantly higher levels of C16:0 and C18:0, but lower levels of C18:1n-9 and C18:2n-6. The liver plays a key role in lipid metabolism, which is active in de novo fatty acid synthesis and ketogenesis $[42,43]$. The synthesis of SFAs in the testis supplies the individual requirements independent of dietary changes [44].
In the adult testis, compared with $\mathrm{NC}$ group, only three fatty acids were significantly different in individual ART group. The sum of SFAs, MUFAs and PUFAs showed no significant difference between the four groups, which indicated that the ART operations probably exert the minimal influence on the fatty acid composition in the testis. However, the fatty acid profiles in the adipose tissue and liver varied in adult mice between $\mathrm{NC}, \mathrm{COH}$, IVF and ICSI group. Compared with the NC mice, ART mice have significantly

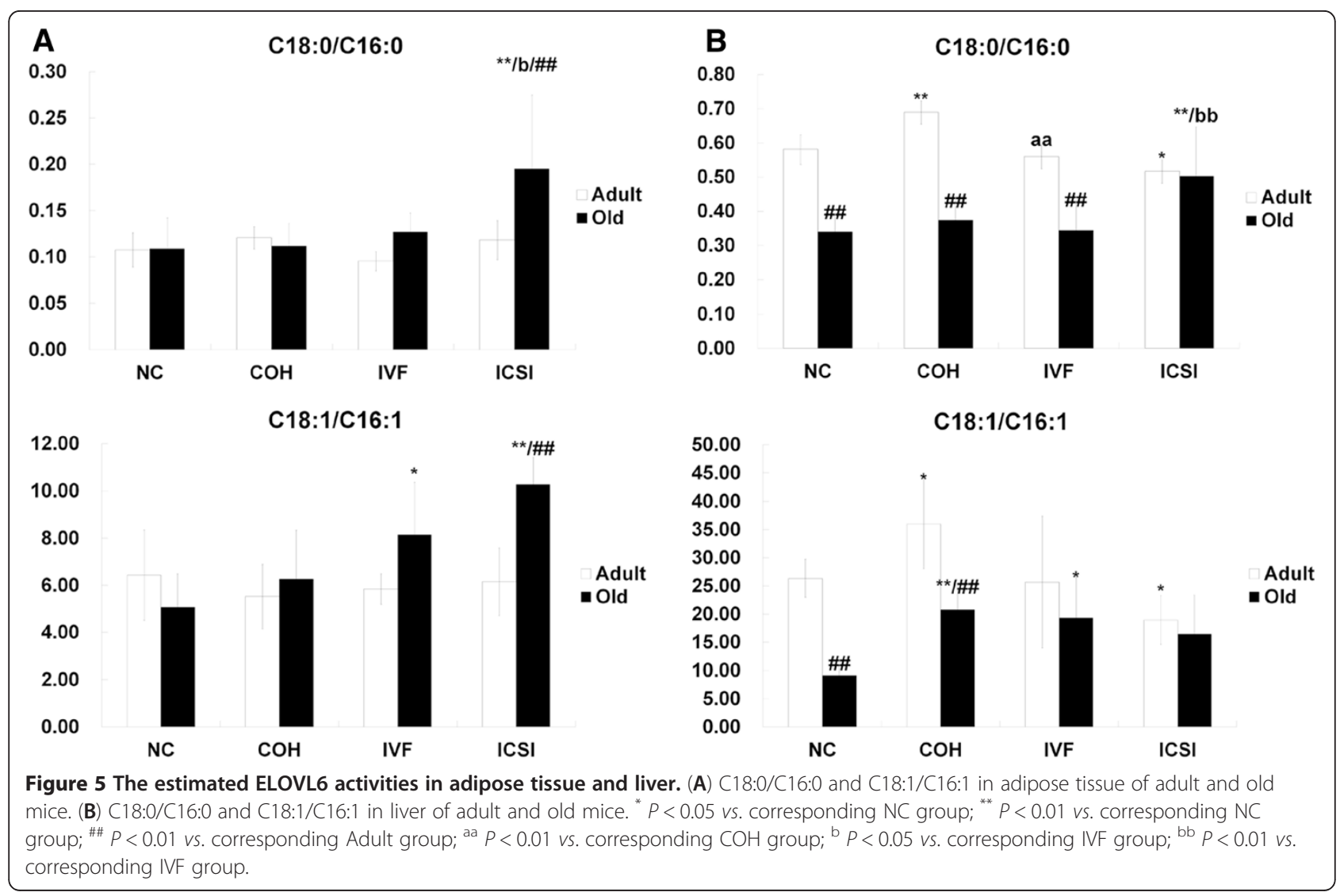




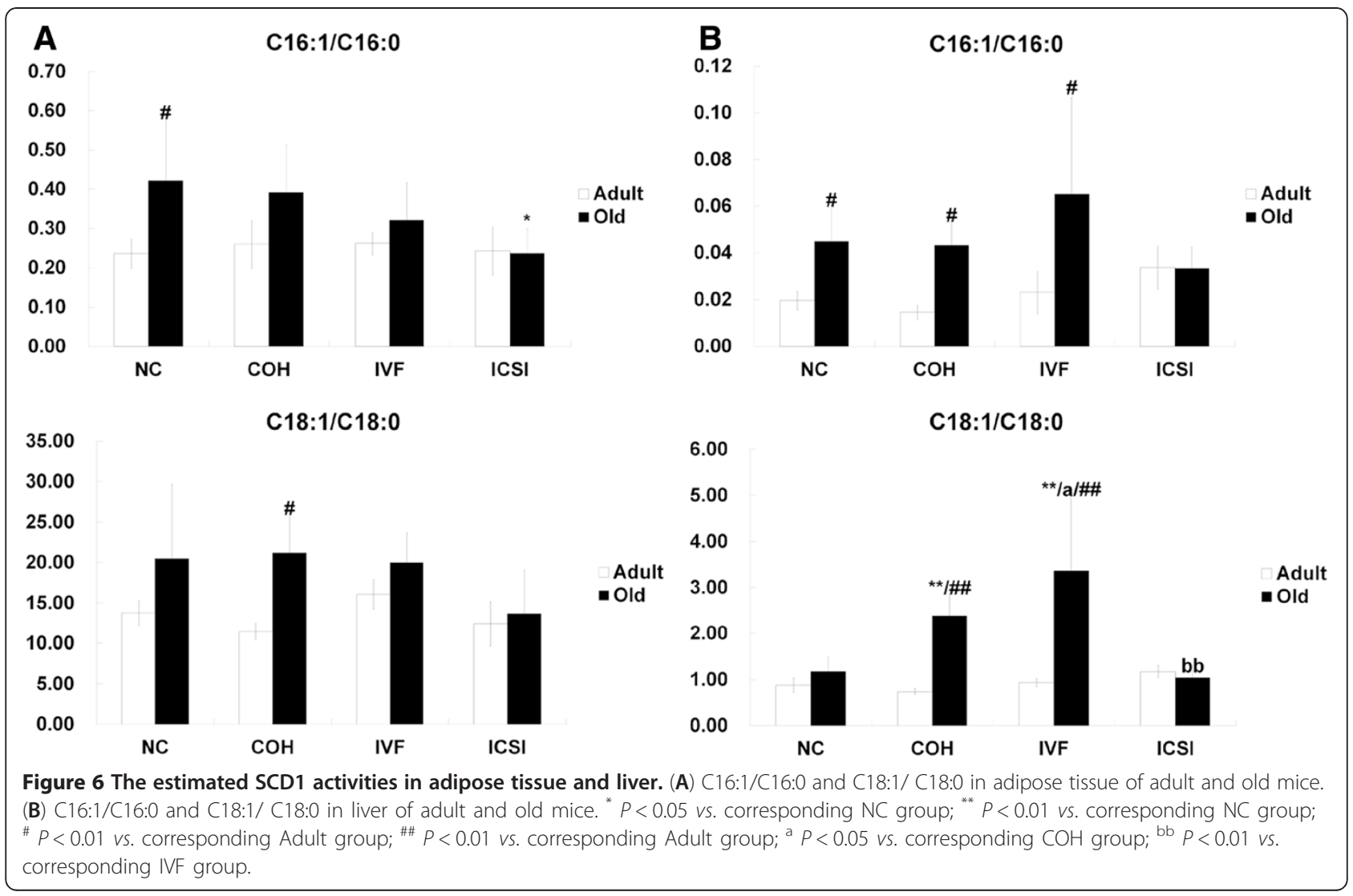

lower levels of PUFAs and higher levels of SFAs. The decrease of PUFAs mainly resulted from C18:2n-6. Antonini FM, Bucalossi A, Petruzzi E, Simoni R, Morini PL and D'Alessandro A [45] have reported that the fatty acid composition of adipose tissue was associated with atherosclerosis and diabetes. Compared to normal people, men with atherosclerosis had lower levels of C18:2n-6 in their adipose tissue. Unlike the adipose tissue, the alteration of fatty acid profile in the liver of ART mice was much more complex. C16:1n-7, one of the increased MUFAs in ICSI group, was reported as an important signaling lipid hormone newly designated as "lipokine", which could stimulate the activity of muscle insulin action and influence fat deposition in the liver [46].
To detect the long-term effect of ART treatments on fatty acid metabolism, the fatty acid composition in old mice were also analyzed. In our results, the SFAs in adipose tissue increased with age and MUFAs decreased with age. In contrast, hepatic PUFAs were downregulated in old mice. These changes were coincident with previous studies $[47,48]$. However, the changes of fatty acid composition between the four groups in old mice were different from those in adult mice. Compared with NC group, $\mathrm{COH}$ and IVF mice showed much more obvious difference than ICSI group. It is probably ART induced inconsistent changes of fatty acid composition during aging.

Since the content of SFAs, MUFAs and PUFAs can be regulated by many desaturases and elongases, and then the

Table 6 The relationship between estimated ELOVL6 and SCD1 activities, de novo synthesis index, C16:0, C16:1n-7, C18:1n-9 and C20:4n-6 in liver

\begin{tabular}{|c|c|c|c|c|c|c|c|c|c|c|c|c|}
\hline \multirow[t]{3}{*}{ Liver } & \multicolumn{4}{|c|}{ Estimated ELOVL6 activity } & \multicolumn{4}{|c|}{ Estimated SCD1 activity } & \multicolumn{2}{|c|}{ C16:0/C18:2n-6 } & \multicolumn{2}{|c|}{ C16:0 } \\
\hline & \multicolumn{2}{|c|}{ C18:0/C16:0 } & \multicolumn{2}{|c|}{ C18:1/C16:1 } & \multicolumn{2}{|c|}{ C16:1/C16:0 } & \multicolumn{2}{|c|}{ C18:1/C18:0 } & & & & \\
\hline & Adult & Old & Adult & Old & Adult & Old & Adult & Old & Adult & Old & Adult & Old \\
\hline $\mathrm{C} 16: 1 \mathrm{n}-7$ & $-0.797^{* *}$ & $-0.718^{* *}$ & $-0.865^{* *}$ & $-0.658^{* *}$ & $0.970^{* *}$ & $0.946^{* *}$ & $0.887^{* *}$ & $0.517^{* *}$ & $0.466^{*}$ & $-0.602^{* *}$ & $0.514^{*}$ & $-0.485^{* *}$ \\
\hline C18:1n-9 & $-0.735^{* *}$ & -0.096 & $-0.508^{*}$ & $0.589^{* *}$ & $0.734^{* *}$ & 0.294 & $0.954^{* *}$ & $0.843^{* *}$ & $0.494^{*}$ & -0.355 & $0.662^{* *}$ & $-0.707^{* *}$ \\
\hline$C 20: 4 n-6$ & $0.727^{* *}$ & -0.016 & $0.618^{* *}$ & $-0.643^{* *}$ & $-0.475^{*}$ & -0.152 & $-0.552^{*}$ & $-0.722^{* *}$ & -0.291 & 0.245 & $-0.735^{* *}$ & $0.560^{* *}$ \\
\hline
\end{tabular}


Table 7 The relationship between estimated ELOVL6 and SCD1 activities, de novo synthesis index, C18:0, C20:2n-6, C20:4n-6 and C22:4n-7 in adipose tissue

\begin{tabular}{|c|c|c|c|c|c|c|c|c|c|c|c|c|}
\hline \multirow[t]{3}{*}{ Adipose tissue } & \multicolumn{4}{|c|}{ Estimated ELOVL6 activity } & \multicolumn{4}{|c|}{ Estimated SCD1 activity } & \multicolumn{2}{|c|}{ C16:0/C18:2n-6 } & \multicolumn{2}{|c|}{ C18:0 } \\
\hline & \multicolumn{2}{|c|}{ C18:0/C16:0 } & \multicolumn{2}{|c|}{ C18:1/C16:1 } & \multicolumn{2}{|c|}{ C16:1/C16:0 } & \multicolumn{2}{|c|}{ C18:1/C18:0 } & & & & \\
\hline & Adult & Old & Adult & Old & Adult & Old & Adult & Old & Adult & Old & Adult & Old \\
\hline$C 20: 2 n-6$ & $-0.497^{* *}$ & $0.792^{* *}$ & -0.08 & $0.743^{* *}$ & 0.338 & $-0.572^{*}$ & $0.613^{* *}$ & $-0.551^{*}$ & $-0.492^{*}$ & 0.104 & $-0.657^{* *}$ & $0.705^{* *}$ \\
\hline C20:4n-6 & $-0.474^{*}$ & $0.485^{*}$ & -0.264 & -0.037 & $0.426^{*}$ & -0.031 & $0.469^{*}$ & -0.315 & $-0.675^{* *}$ & 0.192 & $-0.653^{* *}$ & $0.525^{*}$ \\
\hline$C 22: 4 n-7$ & $-0.438^{*}$ & $0.561^{*}$ & -0.041 & 0.279 & 0.161 & $-0.570^{*}$ & $0.495^{*}$ & $-0.730^{* *}$ & -0.13 & $0.546^{*}$ & $-0.476^{*}$ & $0.717^{* *}$ \\
\hline
\end{tabular}

${ }^{*} P<0.05 ;{ }^{* *} P<0.01$.

activities of these enzymes were analyzed between NC group and ART groups. The results showed the activities of fatty acid metabolism-related enzymes can also be influenced by both ART treatments and aging. According to the correlation analysis, SFAs (C16:0 in liver and C18:0 in adipose tissue) was closely associated with the relationship between fatty acid content and the lipid metabolism-related enzyme activities, which suggested that the variation of SFAs content may be the crucial step for regulating fatty acid composition.

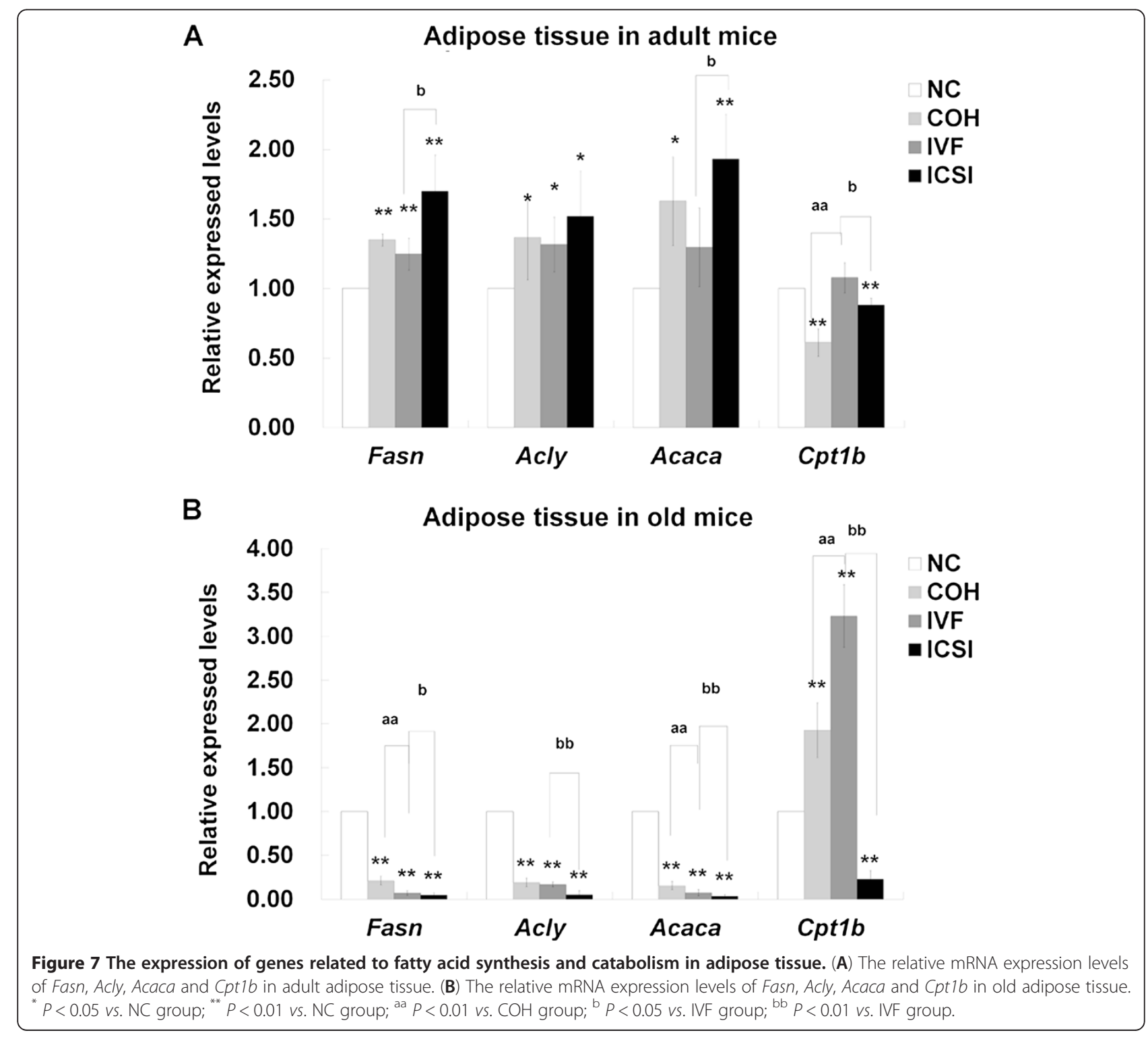




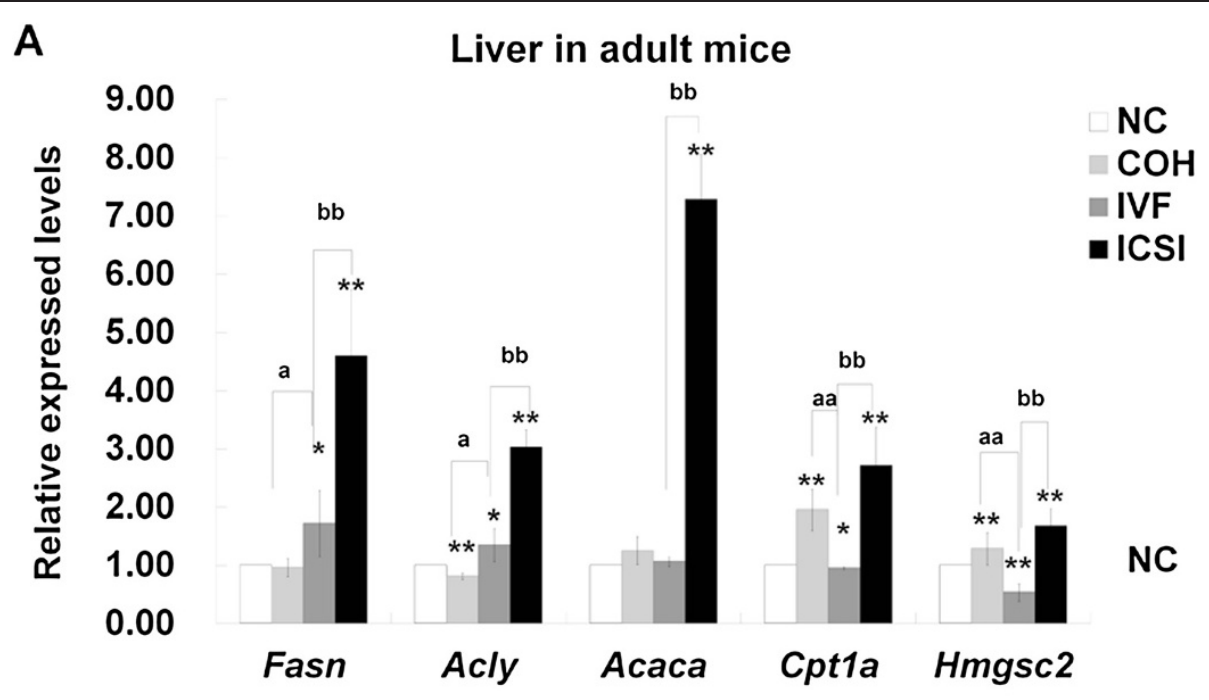

B

\section{Liver in old mice}
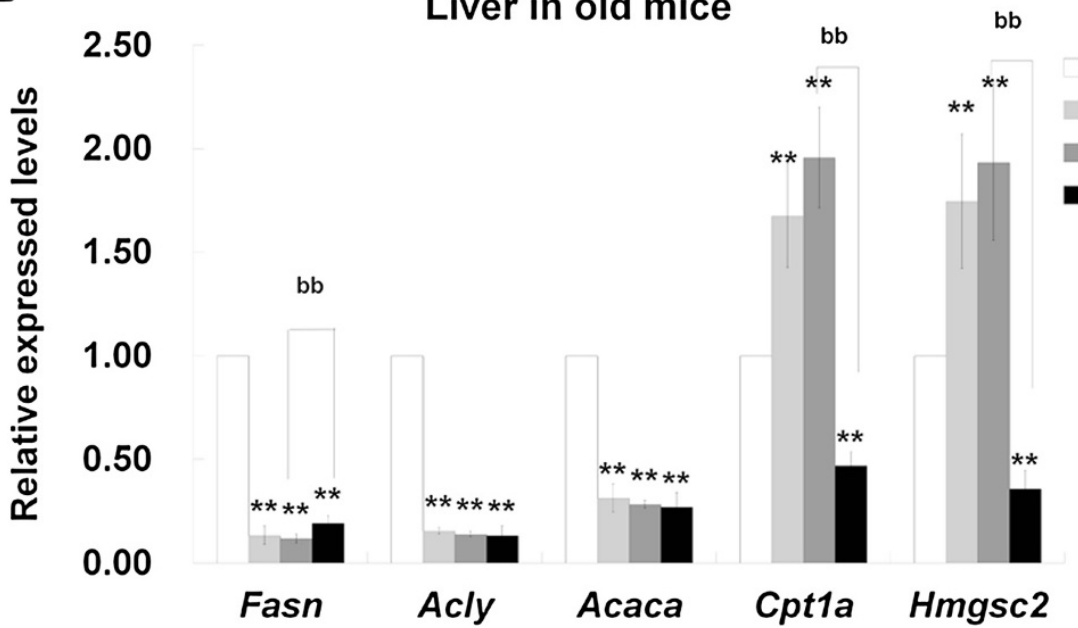

Figure 8 The expression of genes related to fatty acid synthesis and catabolism in liver. (A) The relative mRNA expression level of Fasn, Acly, Acaca, Cpt1a and Hmgsc2 in adult liver. (B) The relative mRNA expression level of Fasn, Acly, Acaca, Cpt1a and Hmgsc2 in old liver. ${ }^{*} P<0.05$ vs. NC group; ${ }^{* *} P<0.01$ vs. NC group; ${ }^{a} P<0.05$ vs. $\mathrm{COH}$ group; ${ }^{\text {aa }} P<0.01$ vs. $\mathrm{COH}$ group; ${ }^{\text {bb }} P<0.01$ vs. IVF group.

Besides desaturases and elongases, lipogenic and lipolytic enzymes also participate in the regulation of fatty acid composition. FAS, ACLY and ACACA are key enzymes in de novo fatty acid synthesis, while CPT1A and $\mathrm{CPT} 1 \mathrm{~B}$ regulate the oxidation of fatty acids in liver and adipose tissue respectively. HMGCS2 determines the first reaction of ketogenesis. The lipid accumulation state can be reflected by the expression of fatty acid synthesis and catabolism-related genes. The increase in fatty acid synthesis, together with the decrease of fatty acid oxidation implied lipid accumulation [29,30]. We concluded the lipid accumulation state in each ART model and each treatment based on the expression of fatty acid synthesis and catabolism-related genes in Tables 8 and 9 . Owing to the inconsistent expression of these genes in each mice model of two age groups, the lipid accumulation state was different. Likewise, we found the lipid accumulation state was generally identical to the changes of SFAs content in both adipose tissue and liver (that is, during the comparison between two groups, the increased lipogenesis and decreased lipolysis accompanied by the up-regulation of SFAs and vice versa). Therefore, the different gene expression of lipogenic and lipolytic enzymes can partly explain the change of fatty acid composition in adult and old ART mice and the variation of SFAs content might also be the crucial step. Interestingly, compared with $\mathrm{NC}$ adult adipose tissue, the enhanced lipid accumulation didn't up-regulate the SFAs content in old mice. It was possible that the total lipid content in adipose tissue had changed with age.

It has been recognized that gonadal hormone can affect lipid metabolism [49], and in vitro culture may increase 

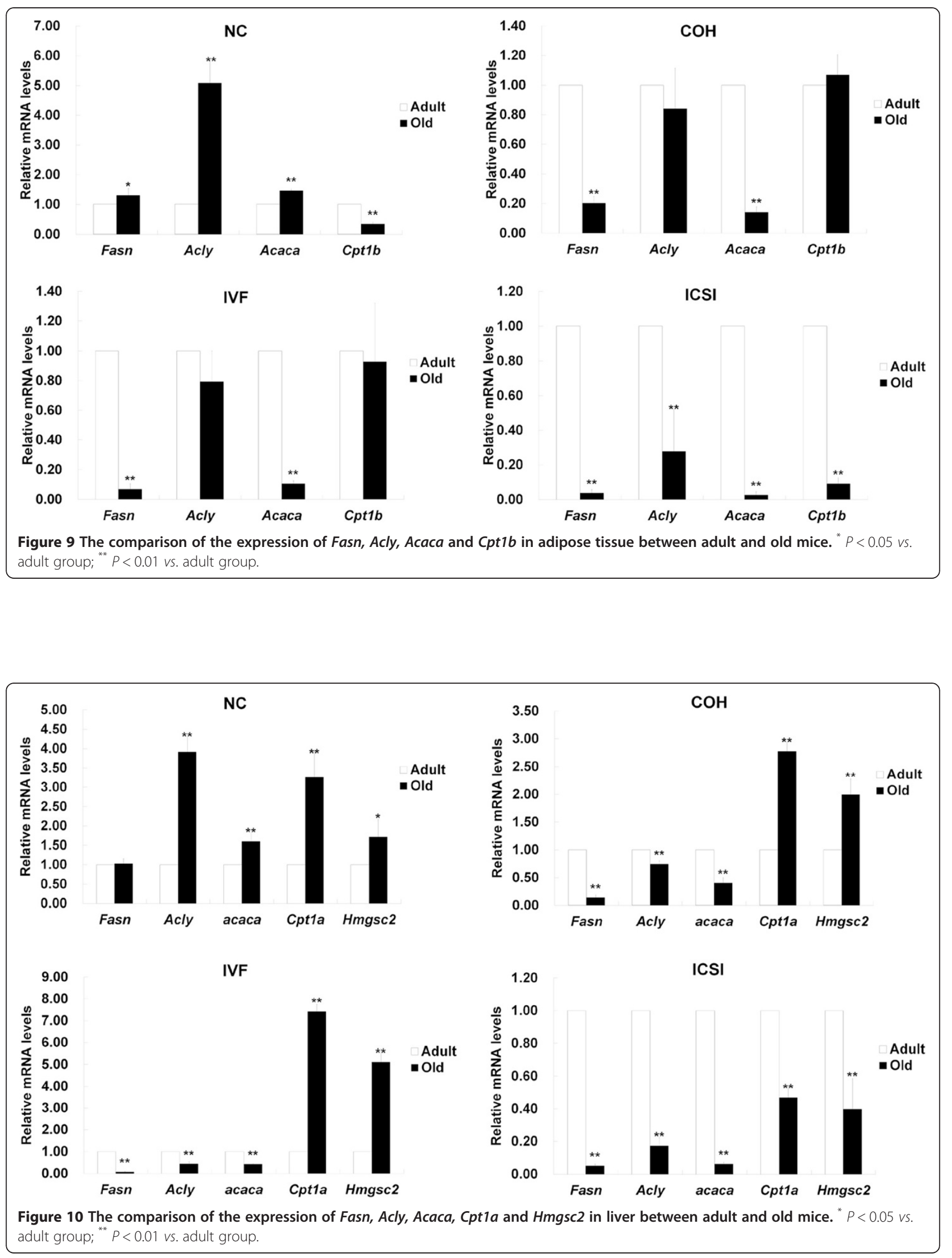
Table 8 The conclusion of lipid accumulation state in adipose tissue

\begin{tabular}{|c|c|c|c|c|c|c|c|}
\hline \multicolumn{2}{|c|}{ Adipose tissue } & \multicolumn{3}{|c|}{ Adult } & \multicolumn{3}{|c|}{ Old } \\
\hline & & Lipogenesis & Lipolysis & lipid accumulation & Lipogenesis & Lipolysis & lipid accumulation \\
\hline \multirow[t]{2}{*}{$\overline{\mathrm{COH}}$} & Superovulation & $\uparrow \uparrow$ & $\downarrow$ & $\uparrow \uparrow$ & $\downarrow$ & $\uparrow$ & $\downarrow$ \\
\hline & In vitro culture & - & $\uparrow$ & $\downarrow$ & $\downarrow$ & - & $\downarrow$ \\
\hline \multirow[t]{2}{*}{ IVF } & & $\uparrow$ & - & $\uparrow$ & $\downarrow$ & $\uparrow$ & $\downarrow$ \\
\hline & Mechanical stimulation & $\uparrow$ & $\downarrow$ & $\uparrow$ & $\downarrow$ & $\downarrow$ & $?$ \\
\hline \multicolumn{2}{|l|}{ ICSI } & $\uparrow$ & $\downarrow$ & $\uparrow$ & $\downarrow$ & $\downarrow$ & $?$ \\
\hline
\end{tabular}

According to the expression of fatty acid synthesis and lipolysis genes, we concluded that the accelerated lipid accumulation derived from increased lipogenesis genes or decreased lipolysis genes, while the opposite expression level implied reduced lipid accumulation.

free oxygen radicals, which probably influences the lipid metabolism of embryos [50]. Mechanical stimulation has been reported to increase lipid-related second messengers [51]. Thus pairwise comparison between $\mathrm{COH}$ and IVF group and between IVF and ICSI group was also made to analyze the effect of in vitro culture and mechanical stimulation on fatty acid metabolism. According to our results, the effect of surperovulation, in vitro culture and mechanical stimulation on fatty acid metabolism changed with age in different tissues, among which the effect of superovulation and in vitro culture induced the reduced lipid accumulation in both adipose tissue and liver of old mice. Fatty acids function as energy provision and signals for metabolic regulation $[52,53]$. Although little research has been involved in the effect of decreased lipid accumulation, these changes must have potential effect on the health of old ART mice.

\section{Conclusion}

Our studies for the first time concentrated on the lipid metabolism in ART male offspring. Fatty acid composition in the adult testis showed little difference between NC and ART groups, while obvious alteration was found in adipose tissue and liver. The differences of fatty acid composition between the four groups in old mice were different from those in adult mice. The effect of ART treatments on fatty acid metabolism changed with age in different tissues, and varied activities and expressions of fatty acid metabolism-related enzymes were the main regulation methods. The alteration of SFAs content may be the crucial step for regulating fatty acid profiles. Although the decreased lipogenesis and increased lipolysis were shown in adipose tissue and liver of $\mathrm{COH}$ and IVF old mice, the effects of these changes need further investigation. Our studies proved the influence of ART on fatty acid composition and the expression of lipid metabolismrelated genes, which could provide a good reference for future investigation of ART safety.

\section{Methods}

\section{ART models}

All the protocols used in our investigation were approved by the Animal Care Ethics Committee of Zhejiang University. All C57BL/6J mice (6-8 weeks old) were randomly divided into four groups ( $\mathrm{NC} / \mathrm{COH} / \mathrm{IVF} / \mathrm{ICSI}$ groups) and raised under a standard environment (room temperature: $23 \pm 1^{\circ} \mathrm{C}$; humidity: $55 \pm 5 \%$ ) with a 12 hours light-dark cycle.

\section{$\mathrm{COH}$ model}

Female mice were injected with 7.5 IU pregnant mare serum gonadotrophin (PMSG) (GEN's, Hangzhou, China) and 7.5 IU human chorionic gonadotrophin (hCG) (GEN's, Hangzhou, China) 48 hours later. After superovulation, the female mice were naturally mated with male mice. $\mathrm{COH}$ embryos at the 2-cell stage were obtained from pregnant mice (appearance of a vaginal plug was designated as 0.5 days) at 1.5 days and transferred to the oviducts of pseudopregnant ICR mice. The $\mathrm{COH}$ mice were born after approximately 3 weeks.

Table 9 The conclusion of lipid accumulation state in liver

\begin{tabular}{|c|c|c|c|c|c|c|c|}
\hline \multirow[t]{2}{*}{ Liver } & & \multicolumn{3}{|c|}{ Adult } & \multicolumn{3}{|c|}{ Old } \\
\hline & & Lipogenesis & Lipolysis & lipid accumulation & Lipogenesis & Lipolysis & lipid accumulation \\
\hline \multirow[t]{2}{*}{$\mathrm{COH}$} & Superovulation & $\downarrow$ & $\uparrow$ & $\downarrow$ & $\downarrow$ & $\uparrow$ & $\downarrow$ \\
\hline & In vitro culture & $\uparrow$ & $\downarrow$ & $\uparrow$ & $\downarrow$ & $\uparrow$ & $\downarrow$ \\
\hline \multirow[t]{2}{*}{ IVF } & & $\uparrow$ & $\downarrow$ & $\uparrow$ & $\downarrow$ & $\uparrow$ & $\downarrow$ \\
\hline & Mechanical stimulation & $\uparrow$ & $\uparrow$ & $?$ & $\uparrow$ & $\downarrow$ & $\uparrow$ \\
\hline ICSI & & $\uparrow$ & $\uparrow$ & $?$ & $\downarrow$ & $\downarrow$ & $?$ \\
\hline
\end{tabular}

According to the expression of fatty acid synthesis and lipolysis genes, we concluded that the accelerated lipid accumulation derived from increased lipogenesis genes or decreased lipolysis genes, while the opposite expression level implied reduced lipid accumulation. 


\section{IVF model}

Female mice were firstly injected with 7.5IU PMSG and 7.5 IU hCG 48 hours later. MII oocytes were obtained 14 hours after hCG injection. IVF-fertilized oocytes were obtained after 6 hours of co-incubation of MII oocytes with sperm, and the fertilization procedure was performed in human tubal fluid (HTF) medium with $10 \%$ serum substitute supplement (SSS) (Irvine Scientific). The IVF-fertilized oocytes were cultured in 10\% SSS G1 medium (Vitrolife). IVF embryos at the 2-cell stage were transferred to the oviducts of pseudopregnant ICR mice, and the IVF mice were born after approximately 3 weeks.

\section{ICSI model}

MII oocytes were obtained after the PMSG-hCG procedure. ICSI injection was operated using an Olympus X71 inverted microscope with PIEZO (PrimeTech, Ibaraki, Japan) and micromanipulators (Narishige, Tokyo, Japan) to obtain ICSI-fertilized oocytes. The fertilization procedure for ICSI was performed in warmed, HEPESbuffered, modified human tubal fluid medium (mHTF) (Irvine Scientific). ICSI-fertilized oocytes were cultured in $10 \%$ SSS G1 medium, and ICSI embryos at the 2-cell stage were transferred to the oviducts of pseudopregnant ICR mice, and the ICSI mice were born after approximately 3 weeks.

The liver, adipose tissue (abdominal adipose), and testis were obtained from three-month old (adult) and 18-month old (old) male mice (each group contained 5 individuals that were not siblings). All tissues were stored at $-80^{\circ} \mathrm{C}$ for further lipid and RNA extraction. All the experiments below were replicated 3 times.

\section{Lipid extraction}

Approximately 0.1 gram of sample (liver, abdominal adipose tissue, testis, and mice diet (Slac, Shanghai China, product number: Q/Scac01-2010)) was put into a tube containing heptadecanoic acid $(0.2 \mathrm{mg} / \mathrm{ml}$, Sigma $)$ as an internal standard, and the lipid extraction from the tissues was performed using chloroform-methanol methods, which was modified based on the procedure used by Wang D-H, Chen Z-J, Jiang Y-Y, Zhou H and Yang W-X [54].

\section{Fatty acid transesterification}

Transesterification was performed in $1 \mathrm{ml}$ of $2 \%$ sulfuric acid-methanol $(\mathrm{v} / \mathrm{v})$ at $60^{\circ} \mathrm{C}$ for 1 hour, and then $2 \mathrm{ml}$ hexane was added to promote fatty acid ester extraction. Subsequently, the fatty acid ester extraction was washed three times with $2 \mathrm{ml} \mathrm{H}_{2} \mathrm{O}$ each time. Moreover, anhydrous sodium sulfate was used to absorb the residual water. Ultimately, the hexane phase was obtained and dried using nitrogen gas, and the fatty acid methyl ester was dissolved in $0.5 \mathrm{ml}$ hexane.

\section{GC-MS and fatty acid analysis}

The fatty acid methyl esters were analyzed by gas chromatography-mass spectrometry (GC-MS) on a Thermo Focus GC/DSQII-MS with a hydrogen flame ionization detector and an HP-5-MS column (30 $\mathrm{m} \times$ $0.25 \mathrm{~mm} \times 0.25 \mu \mathrm{m})$. Helium served as the carrier gas, and $1 \mu \mathrm{l}$ sample was loaded when the injection temperature was $260^{\circ} \mathrm{C}$. The column temperature program was set as follows: $140^{\circ} \mathrm{C}$ for $2 \mathrm{~min} ; 140^{\circ} \mathrm{C}$ to $170^{\circ} \mathrm{C}$ at $4^{\circ} \mathrm{C} / \mathrm{min} ; 170^{\circ} \mathrm{C}$ for $1 \mathrm{~min} ; 170^{\circ} \mathrm{C}$ to $240^{\circ} \mathrm{C}$ at $3.5^{\circ} \mathrm{C} / \mathrm{min} ; 240^{\circ} \mathrm{C}$ for $12.5 \mathrm{~min}$; and $240^{\circ} \mathrm{C}$ to $260^{\circ} \mathrm{C}$ at $12^{\circ} \mathrm{C} / \mathrm{min}$. The detector temperature was $260^{\circ} \mathrm{C}$. Fatty acid methyl esters were identified using MS databases.

\section{Quantitative real-time RT-PCR (qRT-PCR)}

Total RNA from the liver and adipose tissue was extracted with Trizol (Invitrogen), and the cDNA was synthesized using purified total RNA and the SYBR PrimeScript ${ }^{\mathrm{TM}}$ RTPCR Kit (Takara). Then, qRT-PCR was performed using the SYBR-Green I kit (Takara) in an ABI 7900 thermocycler [55]. Gapdh served as an internal control for analyzing gene expression. The primer sequences for qRT-PCR were shown in Additional file 2: Table S2.

\section{Analytical methods of fatty acids}

De novo synthesis index were reflected by $\mathrm{C} 16: 0 / \mathrm{C} 18: 2$ [56]. C18:0/C16:0 and C18:1/C16:1 were used to estimate the activities of EOLVL6, and both C18:1/C18:0 and $C 16: 1 / C 16: 0$ were used to estimate the activities of SCD1 [16].

\section{Statistical analysis}

SPSS 16.0 (SPSS Inc., Chicago, IL, USA) was used for the statistical evaluation. The qRT-PCR data were analyzed by the comparative CT method. One-way ANOVAs (Dunnett's test) followed by the independent-sample $t$ test was used for analyzing the alterations of fatty acid composition, the activities of fatty acid metabolism-related enzymes and gene expression. The correlation between the fatty acids proportion and the activities of fatty acid metabolismrelated enzymes was analyzed by the Pearson correlation coefficient. The confidence interval was $95 \%$.

\section{Additional files}

Additional file 1: Table S1. Relationship between SFAs, MUFAs, PUFAs, estimated ELOVL6 and SCD1 activities and de novo synthesis index.

Additional file 2: Table S2. List of the primers used for qRT-PCR.

\section{Abbreviations}

ACACA: Acetyl-coenzyme A carboxylase alpha; ACLY: ATP citrate lyase; ART: Assisted reproductive technologies; $\mathrm{COH}$ : Controlled ovarian hyperstimulation; CPT: Carnitine palmitoyltransferase; DHA: Docosahexaenoic acid; ELOVL6: ELOVL Family Member 6; FAS: Fatty acid synthase; FSH: Folliclestimulating hormone; GC-MS: Gas chromatography-mass spectrometry; 
HCG: Human chorionic gonadotrophin; HMGCS: Mitochondrial HMG-CoA synthase; HTF: Human tubal fluid; ICSI: Intracytoplasmic sperm injection; IVF: In vitro fertilization; MII: Metaphase II; MUFAs: Monounsaturated fatty acids; $\mathrm{N}_{2}$ : Nitrogen gas; PMSG: Pregnant mare serum gonadotropin; qRTPCR: Quantitative real time RT-PCR; SCD1: Stearoyl-CoA desaturase-1; SFAs: Saturated fatty acids; SSS: Serum substitute supplement; PUFAs: Polyunsaturated fatty acids.

\section{Competing interests}

The authors declare that there is no conflict of interest that could be perceived as prejudicing the impartiality of the research reported.

\section{Authors' contributions}

LYW participated in the design of the study, carried out the molecular biological studies and drafted the manuscript. FL, NW and LL carried out the establishment of ART mice models. YMZ, HYL, XRX, XMZ and HFH participated in the design of the study. YLC performed the statistical analysis. FJ conceived the study, participated in the design and helped to draft the manuscript. All authors read and approved the final manuscript.

\section{Acknowledgement}

This work was supported by the National Basic Research Program of China (grant numbers: 2007CB948104 and 2012CB9401), the National Science Foundation of China (grant numbers: 81070532, 81070541 and 81200475) and the Natural Science Foundation Projects of Zhejiang Province (grant numbers: Y2090084)

We thank Ms. Li-Juan Mao, the technician of the 985-Institute of Agrobiology and Environmental Sciences of Zhejiang University, for her contribution in GC-MS analysis.

\section{Author details}

${ }^{1}$ Centre of Reproductive Medicine, Women's Hospital, School of Medicine, Zhejiang University, Hangzhou 310006, China. ${ }^{2}$ Key Laboratory of Reproductive Genetics (Zhejiang), Ministry of Health, Hangzhou 310006, China. ${ }^{3}$ Department of Gynecologic Oncology, Henan Cancer Hospital, Zhengzhou 450003, China. ${ }^{4}$ College of Life Science, Zhejiang University, Hangzhou 310058, China.

Received: 1 December 2012 Accepted: 19 January 2013

Published: 23 January 2013

\section{References}

1. Kurinczuk JJ: Safety issues in assisted reproduction technology. From theory to reality--just what are the data telling us about ICSI offspring health and future fertility and should we be concerned? Hum Reprod 2003, 18:925-931.

2. Reefhuis J, Honein MA, Schieve LA, Correa A, Hobbs CA, Rasmussen SA: Assisted reproductive technology and major structural birth defects in the United States. Hum Reprod 2009, 24:360-366.

3. Reddy UM, Wapner RJ, Rebar RW, Tasca RJ: Infertility, assisted reproductive technology, and adverse pregnancy outcomes: executive summary of a National Institute of Child Health and Human Development workshop. Obstet Gynecol 2007, 109:967-977.

4. Shevell T, Malone FD, Vidaver J, Porter TF, Luthy DA, Comstock CH, Hankins GD, Eddleman K, Dolan S, Dugoff L, et al: Assisted reproductive technology and pregnancy outcome. Obstet Gynecol 2005, 106:1039-1045.

5. Gavriil P, Jauniaux E, Leroy F: Pathologic examination of placentas from singleton and twin pregnancies obtained after in vitro fertilization and embryo transfer. Pediatr Pathol 1993, 13:453-462.

6. Van Thuan N, Wakayama S, Kishigami S, Ohta H, Hikichi T, Mizutani E, Bui HT, Wakayama T: Injection of somatic cell cytoplasm into oocytes before intracytoplasmic sperm injection impairs full-term development and increases placental weight in mice. Biol Reprod 2006, 74:865-873

7. Collier AC, Miyagi SJ, Yamauchi Y, Ward MA: Assisted reproduction technologies impair placental steroid metabolism. J Steroid Biochem Mol Biol 2009, 116:21-28.

8. Sumida C: Fatty acids: ancestral ligands and modern co-regulators of the steroid hormone receptor cell signalling pathway. Prostaglandins Leukot Essent Fatty Acids 1995, 52:137-144.
9. Watanabe S, Tani T, Seno M: Effects of free fatty acids on the binding of steroid hormones to bovine serum albumin. Lipids 1990, 25:633-638.

10. Ailhaud G, Guesnet P: Fatty acid composition of fats is an early determinant of childhood obesity: a short review and an opinion. Obes Rev 2004, 5:21-26.

11. Mozaffarian D, Katan MB, Ascherio A, Stampfer MJ, Willett WC: Trans fatty acids and cardiovascular disease. N Engl J Med 2006, 354:1601-1613.

12. Phinney SD: Fatty acids, inflammation, and the metabolic syndrome. Am J Clin Nutr 2005, 82:1151-1152.

13. Fernandez-Real JM, Broch M, Vendrell J, Ricart W: Insulin resistance, inflammation, and serum fatty acid composition. Diabetes Care 2003, 26:1362-1368

14. Kennedy A, Martinez K, Chuang CC, LaPoint K, Mclntosh M: Saturated fatty acid-mediated inflammation and insulin resistance in adipose tissue: mechanisms of action and implications. J Nutr 2009, 139:1-4.

15. Kingsbury KJ, Brett C, Stovold R, Chapman A, Anderson J, Morgan DM: Abnormal fatty acid composition and human atherosclerosis. Postgrad Med J 1974, 50:425-440.

16. Kotronen A, Seppanen-Laakso T, Westerbacka J, Kiviluoto T, Arola J, Ruskeepaa AL, Yki-Jarvinen H, Oresic M: Comparison of lipid and fatty acid composition of the liver, subcutaneous and intra-abdominal adipose tissue, and serum. Obesity (Silver Spring) 2010, 18:937-944.

17. Ohrvall M, Tengblad S, Gref CG, Salminen I, Aro A, Vessby B: Serum alpha tocopherol concentrations and cholesterol ester fatty acid composition in 70-year-old men reflect those 20 years earlier. Eur J Clin Nutr 1996, 50:381-385

18. Ferguson EM, Leese $\mathrm{HJ}$ : A potential role for triglyceride as an energy source during bovine oocyte maturation and early embryo development. Mol Reprod Dev 2006, 73:1195-1201.

19. Kim JY, Kinoshita M, Ohnishi M, Fukui Y: Lipid and fatty acid analysis of fresh and frozen-thawed immature and in vitro matured bovine oocytes. Reproduction 2001, 122:131-138.

20. Wakefield SL, Lane M, Schulz SJ, Hebart ML, Thompson JG, Mitchell M: Maternal supply of omega-3 polyunsaturated fatty acids alter mechanisms involved in oocyte and early embryo development in the mouse. Am J Physiol Endocrinol Metab 2008, 294:E425-E434.

21. Baguma-Nibasheka M, Brenna JT, Nathanielsz PW: Delay of preterm delivery in sheep by omega-3 long-chain polyunsaturates. Biol Reprod 1999, 60:698-701.

22. Robinson RS, Pushpakumara PG, Cheng Z, Peters AR, Abayasekara DR, Wathes DC: Effects of dietary polyunsaturated fatty acids on ovarian and uterine function in lactating dairy cows. Reproduction 2002, 124:119-131.

23. Simopoulos AP: Omega-3 fatty acids in inflammation and autoimmune diseases. J Am Coll Nutr 2002, 21:495-505.

24. Trujillo EP, Broughton KS: Ingestion of $n-3$ polyunsaturated fatty acids and ovulation in rats. J Reprod Fertil 1995, 105:197-203.

25. Davis JT, Coniglio JG: The effect of cryptorchidism, cadmium and antispermatogenic drugs on fatty acid composition of rat testis. J Reprod Fertil 1967, 14:407-413.

26. Aksoy Y, Aksoy H, Altinkaynak K, Aydin HR, Ozkan A: Sperm fatty acid composition in subfertile men. Prostaglandins Leukot Essent Fatty Acids 2006, 75:75-79.

27. Tavilani H, Doosti M, Abdi K, Vaisiraygani A, Joshaghani HR: Decreased polyunsaturated and increased saturated fatty acid concentration in spermatozoa from asthenozoospermic males as compared with normozoospermic males. Andrologia 2006, 38:173-178.

28. Lavrentyev EN, Matta SG, Cook GA: Expression of three carnitine palmitoyltransferase-I isoforms in 10 regions of the rat brain during feeding, fasting, and diabetes. Biochem Biophys Res Commun 2004, 315:174-178.

29. Li K, Li L, Yang GY, Liu H, Li SB, Boden G: Effect of short hairpin RNAmediated adiponectin/Acrp30 down-regulation on insulin signaling and glucose uptake in the 3T3-L1 adipocytes. J Endocrinol Invest 2010, 33:96-102.

30. Pettinelli P, Del Pozo T, Araya J, Rodrigo R, Araya AV, Smok G, Csendes A, Gutierrez L, Rojas J, Korn O, et al: Enhancement in liver SREBP-1C/PPARalpha ratio and steatosis in obese patients: correlations with insulin resistance and $\mathrm{n}-3$ long-chain polyunsaturated fatty acid depletion. Biochim Biophys Acta 2009, 1792:1080-1086. 
31. Capanni M, Calella F, Biagini MR, Genise S, Raimondi L, Bedogni G, SvegliatiBaroni G, Sofi F, Milani S, Abbate R, et al: Prolonged n-3 polyunsaturated fatty acid supplementation ameliorates hepatic steatosis in patients with non-alcoholic fatty liver disease: a pilot study. Aliment Pharmacol Ther 2006, 23:1143-1151.

32. Scaglia N, Igal RA: Inhibition of Stearoyl-CoA Desaturase 1 expression in human lung adenocarcinoma cells impairs tumorigenesis. Int J Oncol 2008, 33:839-850.

33. Matsuzaka T, Shimano H: Elovl6: a new player in fatty acid metabolism and insulin sensitivity. J Mol Med (Berl) 2009, 87:379-384.

34. Funke S, Flach E, Kiss I, Sandor J, Vida G, Bodis J, Ertl T: Male reproductive tract abnormalities: more common after assisted reproduction? Early Hum Dev 2010, 86:547-550.

35. Mau Kai C, Main KM, Andersen AN, Loft A, Skakkebaek NE, Juul A: Reduced serum testosterone levels in infant boys conceived by intracytoplasmic sperm injection. J Clin Endocrinol Metab 2007, 92:2598-2603.

36. Jensen TK, Jorgensen N, Asklund C, Carlsen E, Holm M, Skakkebaek NE: Fertility treatment and reproductive health of male offspring: a study of 1,925 young men from the general population. Am J Epidemiol 2007, 165:583-590.

37. Field CJ, Clandinin MT: Modulation of adipose tissue fat composition by diet: A review. Nutr Res 1984, 4:743-755.

38. Leveille GA: In vivo fatty acid synthesis in adipose tissue and liver of meal-fed rats. Proc Soc Exp Biol Med 1967, 125:85-88.

39. Awad AB: Effect of dietary lipids on composition and glucose utilization by rat adipose tissue. J Nutr 1981, 111:34-39.

40. Weber N, Schonwiese S, Klein E, Mukherjee KD: Adipose tissue triacylglycerols of rats are modulated differently by dietary isomeric octadecenoic acids from coriander oil and high oleic sunflower oil. $J$ Nutr 1999, 129:2206-2211.

41. Perona JS, Portillo MP, Teresa Macarulla M, Tueros Al, Ruiz-Gutierrez V: Influence of different dietary fats on triacylglycerol deposition in rat adipose tissue. Br J Nutr 2000, 84:765-774.

42. Korchak HM: Regulation of hepatic lipogenesis. Tufts Folia Med 1962, 8:134-143.

43. Hellerstein MK: De novo lipogenesis in humans: metabolic and regulatory aspects. Eur J Clin Nutr 1999, 53(Suppl 1):S53-S65.

44. Whorton AR, Coniglio JG: Fatty acid synthesis in testes of fat-deficient and fat-supplemented rats. J Nutr 1977, 107:79-86.

45. Antonini FM, Bucalossi A, Petruzzi E, Simoni R, Morini PL, D'Alessandro A: Fatty acid composition of adipose tissue in normal, atherosclerotic and diabetic subjects. Atherosclerosis 1970, 11:279-289.

46. Cao H, Gerhold K, Mayers JR, Wiest MM, Watkins SM, Hotamisligil GS: Identification of a Lipokine, a Lipid Hormone Linking Adipose Tissue to Systemic Metabolism. Cell 2008, 134:933-944.

47. Smith SB, Go GW, Johnson BJ, Chung KY, Choi SH, Sawyer JE, Silvey DT, Gilmore LA, Ghahramany G, Kim KH: Adipogenic gene expression and fatty acid composition in subcutaneous adipose tissue depots of Angus steers between 9 and 16 months of age. J Anim Sci 2012 90:2505-2514.

48. Malau-Aduli AEO, Edriss MA, Siebert BD, Bottema CDK, Pitchford WS: Breed differences and genetic parameters for melting point, marbling score and fatty acid composition of lot-fed cattle. J Anim Physiol Anim Nutr 2000, 83:95-105

49. Aftergood L, Alfin-Slater RB: Dietary and gonadal hormone effects on lipid metabolism in the rat. J Lipid Res 1965, 6:287-294.

50. Burton GJ, Hempstock J, Jauniaux E: Oxygen, early embryonic metabolism and free radical-mediated embryopathies. Reprod Biomed Online 2003, 6:84-96.

51. Vandenburgh HH, Shansky J, Karlisch P, Solerssi RL: Mechanical stimulation of skeletal muscle generates lipid-related second messengers by phospholipase activation. J Cell Physiol 1993, 155:63-71.

52. Saltiel $A R$, Kahn CR: Insulin signalling and the regulation of glucose and lipid metabolism. Nature 2001, 414:799-806.

53. Hotamisligil GS: Inflammation and metabolic disorders. Nature 2006, 444:860-867.

54. Wang D-H, Chen Z-J, Jiang $Y-Y$, Zhou H, Yang W-X: Fatty acid composition and analysis of freshwater caridean shrimp Macrobrachium nipponense (De Haan) during spermiogenesis. Aquacult Res 2010, 41:1140-1149.
55. Li L, Wang L, Xu X, Lou H, Le F, Sheng J, Huang H, Jin F: Genome-wide DNA methylation patterns in IVF-conceived mice and their progeny: a putative model for ART-conceived humans. Reprod Toxicol 2011, 32:98-105.

56. Peter A, Cegan A, Wagner S, Lehmann R, Stefan N, Konigsrainer A Konigsrainer I, Haring HU, Schleicher E: Hepatic lipid composition and stearoyl-coenzyme A desaturase 1 mRNA expression can be estimated from plasma VLDL fatty acid ratios. Clin Chem 2009, 55:2113-2120.

doi:10.1186/1476-511X-12-5

Cite this article as: Wang et al:: Alteration of fatty acid metabolism in the liver, adipose tissue, and testis of male mice conceived through assisted reproductive technologies: fatty acid metabolism in ART mice. Lipids in Health and Disease 2013 12:5.

\section{Submit your next manuscript to BioMed Central and take full advantage of:}

- Convenient online submission

- Thorough peer review

- No space constraints or color figure charges

- Immediate publication on acceptance

- Inclusion in PubMed, CAS, Scopus and Google Scholar

- Research which is freely available for redistribution 